\title{
Dynamic modelling of hydrogen evolution effects in the all-vanadium redox flow battery
}

\author{
A.A. Shah*, H. Al-Fetlawi, F.C. Walsh \\ Electrochemical Engineering Laboratory, Energy Technology Research Group, School of Engineering Sciences, University of Southampton, University Road, \\ Southampton SO17 1BJ, United Kingdom
}

\section{A R T I C L E I N F O}

\section{Article history:}

Received 24 June 2009

Received in revised form 7 October 2009

Accepted 8 October 2009

Available online 31 October 2009

\section{Keywords:}

Bubble formation

Flow battery

Hydrogen evolution

Mathematical model

Numerical simulation

\begin{abstract}
A B S T R A C T
A model for hydrogen evolution in an all-vanadium redox flow battery is developed, coupling the dynamic conservation equations for charge, mass and momentum with a detailed description of the electrochemical reactions. Bubble formation at the negative electrode is included in the model, taking into account the attendant reduction in the liquid volume and the transfer of momentum between the gas and liquid phases, using a modified multiphase-mixture approach. Numerical simulations are compared to experimental data for different vanadium concentrations and mean linear electrolyte flow rates, demonstrating good agreement. Comparisons to simulations with negligible hydrogen evolution demonstrate the effect of gas evolution on the efficiency of the battery. The effects of reactant concentration, flow rate, applied current density and gas bubble diameter on hydrogen evolution are investigated. Significant variations in the gas volume fraction and the bubble velocity are predicted, depending on the operating conditions.
\end{abstract}

(c) 2009 Elsevier Ltd. All rights reserved.

\section{Introduction}

The delivery of electrical energy converted from renewable resources such as wind and solar, which typically suffer from intermittency problems, is highly dependent on reliable and economical energy storage systems. The redox flow battery (RFB), examples of which include the all-vanadium, vanadium/bromide, zinc-cerium and soluble lead-acid cells [1], is a particularly promising technology in this and other application areas, including load levelling and peak shaving, un-interruptible power supply and emergency backup [2].

Perhaps the most developed of the RFB types is the all-vanadium battery [2-5]. In contrast to conventional batteries such as lead-acid storage cells, energy is stored externally to the cell, in two solutions containing different redox couples: $\mathrm{V}(\mathrm{II}) / \mathrm{V}(\mathrm{II})$ and $\mathrm{V}(\mathrm{IV}) / \mathrm{V}(\mathrm{V})$. The capacity of the system is determined by the volume of the electrolyte tanks and the concentrations of the reactants, while the system power is determined by the size of the stacks and the active electrode surface area; scale-up of the system is conceptually straightforward and suits a modular approach. There are several other advantages to RFB technology over some of the established technologies such as static lead-acid batteries [1,2]. Chief amongst these are the high energy efficiencies, a decreasing cost per kWh at higher storage capacity and ease of maintenance. The

\footnotetext{
* Corresponding author. Tel.: +44 (0)23 8059 8520; fax: +44 (0)23 80593131

E-mail address: A.Shah@soton.ac.uk (A.A. Shah).
}

use of the same element in both half-cells also avoids problems of cross-contamination during long-term use.

Several challenges remain in optimising and improving current designs, particularly with respect to scale-up, minimisation of gas evolution, improved electrolyte stability, resistance to carbon oxidation and membrane fouling. There are a number of effects associated with hydrogen and oxygen evolution, which are currently not well understood. These effects must be well characterised to determine the optimal window of operating space for acceptable performance and longevity of the cell. Gas evolving reactions are parasitic, consuming a portion of the current applied to the cell. Characteristic of gas evolving cells is the formation of gas bubbles. The presence of the bubbles reduces the liquid-phase volume in the electrodes, leading to a restricted flow of the electrolyte, a reduced active surface area for reaction, and to reduced transport coefficients. On the other hand, the buoyancy of the bubbles can enhance the flow rate and turbulence can enhance mixing [6].

Extensive laboratory testing of different materials, components and additives over a broad range of conditions is time-consuming and comes at a high financial cost. Modelling and simulation tools, suitably validated, are cost-effective methods for reducing the number of test cases. In contrast to conventional batteries such as the lead-acid and lithium-ion cells [7-10], however, there are few examples of RFB models based on the fundamental conservation principles, with detailed descriptions of the transport phenomena and electrochemical reactions. Notable exceptions include the models developed by Shah et al. [11] and Li and Hikihara [12] for the all-vanadium system and by Scamman et al. [13] for the 
bromine-polysulphide battery. In this paper, the two-dimensional, transient model of Shah et al. is extended to incorporate the effects of $\mathrm{H}_{2}$ evolution and bubble formation. The formation and effects of gas bubble evolution on planar electrodes, particularly from $\mathrm{H}_{2}$ evolution, has been investigated fairly extensively [14-18]. Analytical and numerical models have been developed, notably by Dahlkild and co-workers [19,20], Ziegler and Evans [15] and Mat and co-workers [21,22], all based on the multi-phase mixture (or 'drift-diffusion') model [23,24]. The same approach towards bubble formation and gas/liquid transport is adopted in this paper.

In the next section, details of the experimental work are provided. Details of the model, including the underlying assumptions, are provided in Section 3. In Section 4, the simulation results are presented and comparisons to the experimental data are made. The effects of varying the vanadium concentrations, the mean linear flow rate of the electrolyte, the applied current and the bubble diameter are discussed in detail. The results are summarised in Section 5 .

\section{Experimental}

The body of the redox flow battery was constructed in polyvinyl chloride polymer. The positive and negative electrode compartments were $10 \mathrm{~cm} \times 10 \mathrm{~cm} \times 0.4 \mathrm{~cm}$ in size. The compartments, which were divided by a Nafion ${ }^{\circledR} 114$ cation exchange membrane, were filled by porous and layered carbon felt electrodes (Sigratherm GFA5). The effective volumetric porosity of the felt electrodes was $68 \pm 7$. Electrolyte was circulated through each half-cell compartment through a glass reservoir (volume $250 \mathrm{~mL}$, with a nitrogen gas atmosphere) and peristaltic pump circuit. The electrolyte contained a total vanadium concentration in the range $1.0-1.5 \mathrm{~mol} \mathrm{dm}^{-3}$, as a V(III) and V(IV) mixture, in $4.0 \mathrm{~mol} \mathrm{dm}^{-3}$ $\mathrm{H}_{2} \mathrm{SO}_{4}$, at a temperature of $297 \pm 2 \mathrm{~K}$. The volumetric flow rate was in the range $60-180 \mathrm{~cm}^{3} \mathrm{~min}^{-1}$, corresponding to a mean linear flow velocity of $0.37-1.1 \mathrm{~cm} \mathrm{~s}^{-1}$ through the carbon felt electrodes. The cell was charged at a constant current (typically in the range $2-10 \mathrm{~A}$, corresponding to a current density of $20-100 \mathrm{~mA} \mathrm{~cm}^{-2}$, based on the projected area of each electrode) and discharged at a constant potential difference until a minimum potential difference of $0.8 \mathrm{~V}$ was achieved. Typically, the charge and discharge parts of a cycle were each $30-40 \mathrm{~min}$ in duration. Up to 30 cycles were used. An in-house personal computer and interface was used to monitor cell potential difference. In addition, an open-circuit cell (divided by a Nafion ${ }^{\circledR} 1135$ cation exchange membrane) was used to monitor the cell potential difference between carbon rod electrodes ( $8 \mathrm{~mm}$ diameter carbon rods). This cell effectively measured the differential redox potential between the half-cell electrolytes, which provided an indication of the state of charge. The cell current was also monitored.

\section{Model assumptions and equations}

The model is based on the two-dimensional slice depicted in Fig. 1, which includes the reservoirs, the porous electrodes, the current collectors and the ion-exchange membrane.

The kinetics of reduction and oxidation of the vanadium-species are known to be highly complex [25,26]. In this paper, the following simplified set of half-cell reactions is adopted:

Negative electrode: $\mathrm{V}(\mathrm{III})+\mathrm{e}^{-} \rightleftharpoons \mathrm{V}(\mathrm{II})$

Positive electrode: $\mathrm{VO}^{2+}+\mathrm{H}_{2} \mathrm{O} \rightleftharpoons \mathrm{VO}_{2}^{+}+2 \mathrm{H}^{+}+\mathrm{e}^{-}$

There are, in addition, several known side reactions, notably the evolution of oxygen in the positive electrode $[26,27]$ and the evolution of $\mathrm{H}_{2}$ in the negative electrode $[26,28]$ on charge; the latter

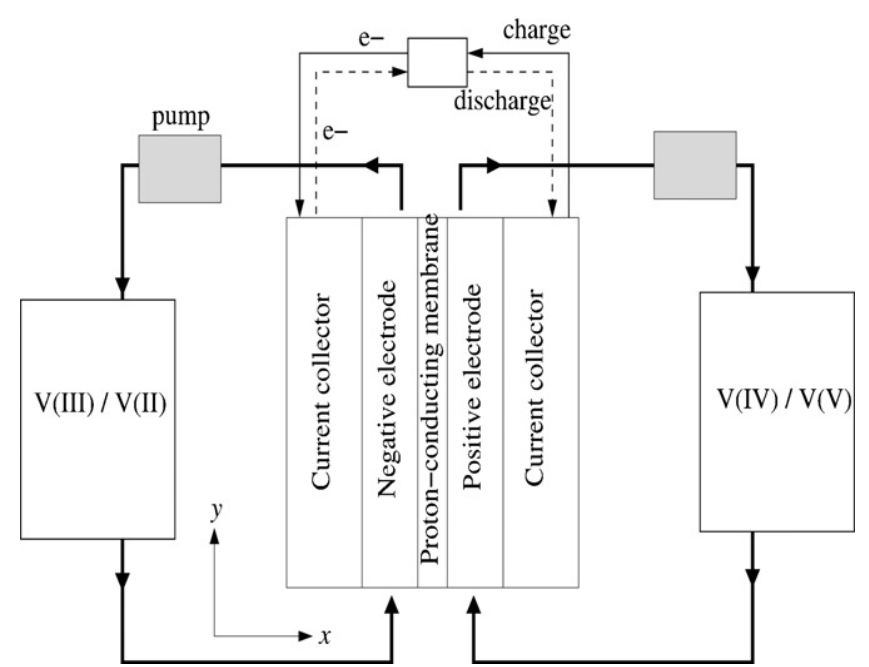

Fig. 1. A schematic of the all-vanadium battery and of the components modelled in this paper: current collectors, porous carbon electrodes, membrane and reservoirs.

proceeds as follows:

$2 \mathrm{H}^{+}+2 \mathrm{e}^{-} \rightleftharpoons \mathrm{H}_{2}$

in an acidic environment. The evolution of $\mathrm{H}_{2}$, reaction (3), will be considered along with the mechanism (1) and (2). The species to be considered, along with their transport by diffusion, migration and convection, are $\mathrm{V}(\mathrm{II}), \mathrm{V}(\mathrm{III}), \mathrm{V}(\mathrm{IV}), \mathrm{V}(\mathrm{V}), \mathrm{H}_{2} \mathrm{O}, \mathrm{H}^{+}, \mathrm{HSO}_{4}^{-}, \mathrm{OH}^{-}$, $\mathrm{H}_{2}$ and $\mathrm{SO}_{4}{ }^{2-}$. In order to formulate a manageable problem, certain simplifying assumptions were made:

1. The dilute-solution approximation [29].

2. Laminar, incompressible flow.

3. The $\mathrm{H}_{2}$ gas forms spherical bubbles that maintain their shape when detaching from the electrode surface (no coalescence).

4. The overall momentum equation (for the gas bubbles and liquid) is approximated by that of the liquid phase.

In addition to isothermal conditions. The first two assumptions can be justified by the fact that the bulk of the fluid is water. Bubble formation at electrodes evolving $\mathrm{H}_{2}$ and other gases is believed to result from supersaturation of dissolved gas in the liquid adjacent to the electrode surface $[14,19]$. The bubbles form at so-called 'nucleation sites' on the electrode surface. In the 'nucleation regime', growing gas bubbles detach from the nucleation sites when the buoyancy and shear forces of the liquid exceed the interfacial tension force adhering the bubbles to the electrode surface. Small (typically sized) bubbles remain spherical as a result of high surface tension and their coalescence can be neglected [16], possibly as a result of repulsive electrical forces acting between the bubbles flowing through an electrolyte [30]. The last assumption is based on the fact that the liquid phase volume fraction and density are much larger than those of the gas phase.

\subsection{Equation in the porous carbon electrode}

The gas bubbles are dispersed, i.e., they do not form a continuous phase, and move with the flow of the liquid phase (denoted with a subscript ' $l$ '). The volume fractions of the gas bubbles and the electrolyte in the pore space, $\alpha_{g}$ and $\alpha_{l}$, respectively, must satisfy volume conservation:

$\alpha_{l}+\alpha_{g}=1$

In the multiphase mixture model [24], the mixture density and mixture velocity (velocity of the mass centre), $\rho_{m}$ and $\vec{u}_{m}$, respectively, 
are defined as follows:

$\rho_{m}=\rho_{l} \alpha_{l}+\rho_{g} \alpha_{g}$

$\vec{u}_{m}=\frac{\rho_{g} \alpha_{g} \vec{u}_{g}+\rho_{l} \alpha_{l} \vec{u}_{l}}{\rho_{m}}$

$\rho_{l}$ and $\rho_{g}$ are the liquid-phase and gas-phase densities and $\vec{u}_{l}$ and $\vec{u}_{g}$ are the liquid-phase and gas-phase velocities, respectively. It is assumed, however, that the liquid-phase dominates, so that the overall momentum equation is approximated by that of the liquid phase. The liquid velocity, $\vec{u}_{l}$ is given by Darcy's law for flow through a porous medium, combined with the Kozeny-Carman law for the hydraulic conductivity [31]:

$\vec{u}_{l}=-\frac{d_{f}^{2}}{K \mu_{l}} \frac{\epsilon^{3}\left(1-\alpha_{g}\right)^{3}}{\left(1-\epsilon\left(1-\alpha_{g}\right)\right)^{2}} \nabla p$

where $p$ is the liquid-phase pressure, $\mu_{l}$ is the dynamic viscosity of the liquid, $d_{f}$ is the mean pore diameter in the electrode and $K$ is the Kozeny-Carman constant for a fibrous medium. Except in the case of expanding bubbles, where surface tension effects are significant, it is customarily assumed that the gas-phase and liquidphase pressures are equal $[32,33]$.

The overall mixture continuity is replaced with the incompressibility constraint (continuity equation for the liquid phase):

$\nabla \cdot \vec{u}_{l}=0$

These assumptions are valid for small gas volume fractions, as is the case in the present problem. They are consistent with an assumption that the flow is dominated by the flow of the liquid, with departures in the bubble velocity from the bulk velocity induced by drag forces, equal in magnitude to the buoyancy force exerted on the bubbles.

In practise, the liquid-phase velocity is eliminated in favour of the pressure, using the continuity equation and Darcy's law, and the following parabolic equation is solved:

$-\nabla \cdot\left(\frac{d_{f}^{2}}{K \mu_{l}} \frac{\epsilon^{3}\left(1-\alpha_{g}\right)^{3}}{\left(1-\epsilon\left(1-\alpha_{g}\right)\right)^{2}} \nabla p\right)=0$

The liquid-phase and gas-phase velocities are related by the slip (relative) velocity, $\vec{u}_{\text {slip }}$ in the following manner:

$\vec{u}_{\text {slip }}=\vec{u}_{g}-\vec{u}_{l}$

An equation for the slip velocity can be derived by performing a force balance on a bubble [24] (without turbulence):

$\frac{1}{2} \rho_{l} C_{D}\left|\vec{u}_{\text {slip }}\right| \vec{u}_{\text {slip }}=\frac{V_{b}}{A_{b}} \nabla p$

where $V_{b}$ and $A_{b}$ are the volume and cross-sectional area of the bubble, respectively, and $C_{D}$ is the drag coefficient. Eq. (10) is derived using the ansatz that the pressure forces acting on the bubble are balanced by the viscous drag, i.e., negligible virtual mass, Basset (boundary layer development), interfacial-pressure and lift forces [34]. For spherical bubbles the volume to cross-sectional area is $2 d_{b} / 3$, where $d_{b}$ is the bubble diameter. For bubbles with a diameter of less than $2 \mathrm{~mm}$, the following expression (Stoke's law) for the drag coefficient is valid [35,34]:

$C_{d}=\frac{24}{R e_{b}} ; \quad R e_{b}=\frac{d_{b} \rho_{l}\left|\vec{u}_{\text {slip }}\right|}{\mu_{l}}$

where $R e_{b}$ is the Reynolds number associated with the bubble flow. Stoke's law is valid for Reynolds numbers below approximately 1000 , well within the regime of $\mathrm{H}_{2}$ bubbles immersed in an electrolyte of density $\sim 1000 \mathrm{~kg} \mathrm{~m}^{-3}$, with typical diameters less than
Table 1

Sources and sinks for the liquid phase Eq. (14).

\begin{tabular}{lll}
\hline Source term & Positive electrode & Negative electrode \\
\hline$S_{g}$ & $\mathrm{n} / \mathrm{a}$ & $-M_{\mathrm{H}_{2}} \nabla \cdot \vec{j}_{\mathrm{H}_{2}} / F$ \\
$S_{2}$ & $\mathrm{n} / \mathrm{a}$ & $\nabla \cdot \vec{j} / F$ \\
$S_{3}$ & $\mathrm{n} / \mathrm{a}$ & $-\nabla \cdot \vec{j} / F$ \\
$S_{4}$ & $\nabla \cdot \vec{j} / F$ & $\mathrm{n} / \mathrm{a}$ \\
$S_{5}$ & $-\nabla \cdot \vec{j} / F$ & $\mathrm{n} / \mathrm{a}$ \\
$S_{\mathrm{H}_{2} \mathrm{O}}$ & $\nabla \cdot \vec{j} / F$ & $\mathrm{n} / \mathrm{a}$ \\
$S_{\mathrm{H}^{+}}$ & $\mathrm{n} / \mathrm{a}$ & $-2 \nabla \cdot \vec{j} / F$ \\
\hline
\end{tabular}

$100 \mu \mathrm{m}$ and velocities on the order of a few $\mathrm{cm} \mathrm{s}^{-1}$. The final form of the slip velocity is, therefore:

$\vec{u}_{\text {slip }}=\frac{d_{b}^{2}}{18 \mu_{l}} \nabla p$

which, using Eq. (9), yields the gas (bubble) velocity once the liquidphase velocity is known. To complete the bubble flow model, and equation for the gas-phase volume fraction is required. A mass balance, taking into account $\mathrm{H}_{2}$ evolution from the electrochemical reaction, gives:

$\epsilon \rho_{g} \frac{\partial \alpha_{g}}{\partial t}+\epsilon \rho_{g} \nabla \cdot\left(\alpha_{g} \vec{u}_{g}\right)=-S_{g}$

where $\epsilon$ is the porosity of the electrode and $S_{g}$ is the rate of $\mathrm{H}_{2}$ evolution, defined in Table 1 and derived below.

Let $c_{i}$ denote the concentration of species $i=2,3,4,5, \mathrm{H}_{2} \mathrm{O}, \mathrm{H}^{+}$, $\mathrm{HSO}_{4}{ }^{-}, \mathrm{OH}^{-}$and $\mathrm{H}_{2}$ (the notation ' 2 ' is used for ' $\mathrm{V}$ (II)' and similarly for the other vanadium species). A volume-averaged mass balance in the porous regions can be expressed in the following form:

$\frac{\partial}{\partial t}\left(\epsilon\left(1-\alpha_{g}\right) c_{i}\right)+\nabla \cdot \vec{N}_{i}=-S_{i}$

where $S_{i}$ is the source term for species $i$, defined in Table 1 and discussed in Section 3.4. The concentration flux, $\vec{N}_{i}$ is given by the Nernst-Planck equation $[29,36]$ for the transport of a charged species by diffusion, convection and migration:

$\vec{N}_{i}=-D_{i}^{\mathrm{eff}} \nabla c_{i}-\frac{z_{i} c_{i}}{R T} D_{i}^{\mathrm{eff}} \nabla \phi_{e}+\vec{u}_{l} c_{i}$

$\phi_{e}$ is the ionic potential in the solution phase and $D_{i}^{\text {eff }}$ and $z_{i}$ are the effective diffusion coefficient and charge for species $i$, respectively. The free-space diffusion coefficient, $D_{i}$ is subject to a Bruggemann correction [37] to account for the tortuosity of the flow path:

$D_{i}^{\mathrm{eff}}=D_{i} \epsilon^{3 / 2}\left(1-\alpha_{g}\right)^{3 / 2}$

The electrolyte is considered to be electrically neutral, that is:

$\sum_{i} z_{i} c_{i}=0$

The concentration of $\mathrm{SO}_{4}{ }^{2-}$ at all times (including $t=0$ ) is determined by condition (16). The other species concentrations are calculated explicitly.

At all points, including the boundaries, the charge entering the electrolyte, $\vec{j}_{e}$, is balanced by the charge leaving the solid phase, $\vec{j}_{s}$ :

$\nabla \cdot \vec{j}_{e}+\nabla \cdot \vec{j}_{s}=0$

Adopting the usual practice in PEMFC modelling, a pseudo-steady state for proton and electron transport is assumed [38-40]. Invoking the electroneutrality condition, the total current density in the electrolyte satisfies:

$\vec{j}=\sum_{i} \vec{j}_{i}=-\sigma_{e} \nabla \phi_{e}-F \sum_{i} z_{i} D_{i}^{\mathrm{eff}} \nabla c_{i}$ 
The effective electrolyte conductivity, $\sigma_{e}$ is given by:

$\sigma_{e}=\frac{F^{2}}{R T} \sum_{i} z_{i}^{2} D_{i}^{\mathrm{eff}} c_{i}$

in which $T$ is the common temperature of the solid, liquid and gas, and $R$ is the molar gas constant. Taking the divergence of Eq. (18) yields the final form of the equation for the ionic potential:

$-\nabla \cdot\left(\sigma_{e} \nabla \phi_{e}+F \sum_{i} z_{i} D_{i}^{\mathrm{eff}} \nabla c_{i}\right)=\nabla \cdot \vec{j}$

The current density $\vec{j}$ has two components, one from the redox reactions and the second arising from the $\mathrm{H}_{2}$ evolution reaction. An expression for $\vec{j}$ is derived below. The electronic potential in the porous carbon electrode is given by Ohm's law:

$-\sigma_{s} \nabla^{2} \phi_{s}=-\nabla \cdot \vec{j}$

where conservation of charge, as expressed by (17), is imposed. $\sigma_{s}=(1-\epsilon)^{3 / 2} \sigma_{f}$ is the effective conductivity of the porous carbon electrode, obtained from the value for the solid material, $\sigma_{f}$ subject to a Bruggemann correction.

\subsection{Membrane and current collectors}

For species (proton and water) transport in the membrane, the formulation of Bernadi and Verbrugge [41] developed for PEMFC applications is employed. An electroneutrality condition is enforced, with the fixed charge sites in the membrane structure ( sulfonic acid groups in the case of Nafion ${ }^{\circledR}$ ) taken as the negatively and positively charged species, respectively. The concentration of water dissolved in the membrane, $c_{\mathrm{H}_{2} \mathrm{O}}$ satisfies the following mass balance, taking into account bulk and dissipative (diffusive) transport:

$\frac{\partial c_{\mathrm{H}_{2} \mathrm{O}}}{\partial t}-\nabla \cdot\left(D_{w} \nabla c_{\mathrm{H}_{2} \mathrm{O}}\right)+\nabla \cdot\left(\vec{u}_{l} c_{\mathrm{H}_{2} \mathrm{O}}\right)=0$

in which $D_{w}$ is the effective diffusion coefficient for water through the membrane. The driving forces for the bulk flow are potential and pressure gradients. The liquid velocity $\vec{u}_{l}$ is given by Schloegl's equation:

$\vec{u}_{l}=-\frac{\kappa_{\phi}}{\mu_{\mathrm{H}_{2} \mathrm{O}}} F c_{\mathrm{H}^{+}} \nabla \phi_{e}-\frac{\kappa_{p}}{\mu_{\mathrm{H}_{2} \mathrm{O}}} \nabla p$

for electrokinetic permeability $\kappa_{\phi}$, hydraulic permeability $\kappa_{p}$, water viscosity $\mu_{\mathrm{H}_{2} \mathrm{O}}$, and proton concentration $c_{\mathrm{H}^{+}}$. An incompressibility condition is used to derive the continuity equation for the liquid water in the membrane:

$\nabla \cdot \vec{u}_{l}=0$

From the electro-neutrality condition, the proton concentration satisfies $c_{\mathrm{H}^{+}}=-z_{f} c_{f}$, where $c_{f}$ is the fixed-charge site concentration in the membrane and $z_{f}$ is the fixed-site charge. Since protons are the only mobile ions, the equation for current conservation can be derived using Eqs. (23) and (7):

$0=\nabla \cdot \vec{j}=-\frac{F^{2}}{R T} D_{\mathrm{H}^{+}} C_{\mathrm{H}^{+}} \nabla^{2} \phi_{e}$

where $D_{\mathrm{H}^{+}}$is the effective diffusion coefficient for the protons.

The electronic potential in the current collectors is given by Ohm's law:

$-\sigma_{s} \nabla^{2} \phi_{s}=0$

where $\sigma_{s}=\sigma_{\text {coll }}$ is the electronic conductivity of the collectors.

\subsection{Pump approximation and inlet conditions}

The movement of the electrolyte solution through the electrode and pump alters the concentrations at the inlet boundaries with time. Invoking conservation of volume, the volumetric flow at the outlet boundaries, which have a cross-sectional area $A_{\text {out }}=L_{t} L_{w}$, is $Q=v_{\text {in }} \in A_{\text {out }}$, where $L_{t}$ is the electrode thickness and $L_{w}$ is the electrode width (see Table 3 for values). From the calculated average concentration at the outflow boundaries:

$c_{i}^{\text {out }}=\frac{1}{L_{t}} \int_{y=h} c_{i} \mathrm{~d} x$

the inlet concentrations are approximated from the following mass balance, which assumes instantaneous mixing and negligible reaction in the reservoir of volume $V$ :

$\frac{\mathrm{d} c_{i}^{\mathrm{in}}}{\mathrm{d} t}=\frac{Q}{V}\left(c_{i}^{\text {out }}-c_{i}^{\mathrm{in}}\right) ; \quad c_{i}^{\mathrm{in}}(0)=c_{i}^{0}$

$c_{i}^{0}$ is the initial concentration of species $i$ (water, vanadium species, protons and anions). The total volume of electrolyte on each side of the battery, $V_{T}$, is the sum of the electrode and the reservoir volumes, $\epsilon h A_{\text {out }}$ and $V$, respectively, where $h$ is the height of the porous carbon electrode. It is assumed that the volume of electrolyte contained in the connecting tubes is negligible.

\subsection{Reaction kinetics}

The reversible redox reactions taking place on the solid surfaces of the porous carbon electrode are described using the Butler-Volmer expression for the transfer current densities, $\nabla \cdot \vec{j}$ and $\nabla \cdot \vec{j}_{+}$, in the negative and positive electrode compartments, respectively. The precise multi-step reaction mechanism is not known, but it has previously been demonstrated that the reversible redox features are well captured by the Bultler-Volmer formulae [11]:

$$
\begin{aligned}
& j_{-}=\nabla \cdot \vec{j}_{-}=A \epsilon\left(1-\alpha_{g}\right) F k_{1}\left(c_{3}^{s}\right)^{\beta_{-}}\left(c_{2}^{s}\right)^{\left(1-\beta_{-}\right)}\left[\exp \left(\frac{F\left(1-\beta_{-}\right) \eta_{-}}{R T}\right)-\exp \left(-\frac{F \beta_{-} \eta_{-}}{R T}\right)\right] \\
& j_{+}=\nabla \cdot \vec{j}_{+}=A \epsilon\left(1-\alpha_{g}\right) F k_{2}\left(c_{4}^{s}\right)^{\beta_{+}}\left(c_{5}^{s}\right)^{\left(1-\beta_{+}\right)}\left[\exp \left(\frac{F\left(1-\beta_{+}\right) \eta_{+}}{R T}\right)-\exp \left(-\frac{F \beta_{+} \eta_{+}}{R T}\right)\right]
\end{aligned}
$$

for the negative and positive electrodes, respectively. In these expressions $A$ is the specific active surface area of the porous carbon electrode (solid-liquid interface); $k_{1}$ and $k_{2}$ are the standard rate constants for reactions ( 1 ) and (2), respectively; $\beta_{ \pm}$and $\left(1-\beta_{ \pm}\right)$ are the anodic and cathodic transfer coefficients, respectively (one electron transfer); and $\eta_{-}$and $\eta_{+}$are the overpotentials in the negative and positive electrode, respectively. The porosity of the electrode is multiplied by a factor $1-\alpha_{g}$ to give the volume fraction of the liquid phase, taking into account the presence of the bubbles. The common assumption $\beta_{+}=\beta_{-}=1 / 2$ is made. The overpotentials are defined as follows:

$\eta_{ \pm}=\phi_{s}-\phi_{e}-E_{0, \pm}$

where $E_{0,-}$ and $E_{0,+}$ are the open circuit potentials for reactions (1) and (2), respectively, estimated from the Nernst equations:

$$
\begin{aligned}
& E_{0,-}=E_{0,-}^{\prime}+\frac{2.33 R T}{F}\left(\ln c_{3}-\ln c_{2}\right) \\
& E_{0,+}=E_{0,+}^{\prime}+\frac{2.33 R T}{F}\left(\ln c_{5}-\ln c_{4}\right)
\end{aligned}
$$

The formal potentials $E_{0,-}^{\prime}$ and $E_{0,+}^{\prime}$ are given in Table 3.

The quantities $c_{i}^{s}$ are the vanadium-species concentrations at the liquid-solid interfaces in the porous regions. They can be related 
to the bulk values, $c_{i}$ by approximately balancing the rate of reaction with the rate of diffusion of reactant to (or from) the electrode surface at steady state (details can be found in [11]):

$$
\begin{aligned}
& c_{4}^{s}=\frac{c_{4}+\epsilon\left(1-\alpha_{g}\right) k_{2} e^{-F\left(\phi_{s}-\phi_{e}-E_{0,+}^{\prime}\right) /(2 R T)}\left(\left(c_{4} / \gamma_{5}\right)+\left(c_{5} / \gamma_{4}\right)\right)}{1+\epsilon\left(1-\alpha_{g}\right) k_{2}\left(\left(1 / \gamma_{5}\right) e^{-F\left(\phi_{s}-\phi_{e}-E_{0,+}^{\prime}\right) /(2 R T)}+\left(1 / \gamma_{4}\right) e^{F\left(\phi_{s}-\phi_{e}-E_{0,+}^{\prime}\right) /(2 R T)}\right)} \\
& c_{5}^{s}=\frac{c_{5}+\epsilon\left(1-\alpha_{g}\right) k_{2} e^{F\left(\phi_{s}-\phi_{e}-E_{0,+}^{\prime}\right) /(2 R T)}\left(\left(c_{4} / \gamma_{5}\right)+\left(c_{5} / \gamma_{4}\right)\right)}{1+\epsilon\left(1-\alpha_{g}\right) k_{2}\left(\left(1 / \gamma_{5}\right) e^{-F\left(\phi_{s}-\phi_{e}-E_{0,+}^{\prime}\right) /(2 R T)}+\left(1 / \gamma_{4}\right) e^{F\left(\phi_{s}-\phi_{e}-E_{0,+}^{\prime}\right) /(2 R T)}\right)}
\end{aligned}
$$

where $\gamma_{4}=D_{4} / d$ and $\gamma_{5}=D_{5} / d$. Similar expressions can be derived for the species at the negative electrode.

The current density associated with the $\mathrm{H}_{2}$ evolution reaction (3), which takes place predominantly during charge at the negative electrode, is approximated by the Tafel relationship, assuming that the rate of the backward reaction is negligible:

$j_{\mathrm{H}_{2}}=\nabla \cdot \vec{j}_{\mathrm{H}_{2}}=-A \epsilon\left(1-\alpha_{g}\right) j_{0, \mathrm{H}_{2}} \exp \left(-\frac{F \beta_{\mathrm{H}_{2}} \eta_{\mathrm{H}_{2}}}{R T}\right)$

$j_{0, \mathrm{H}_{2}}$ is the exchange current density and $\eta_{\mathrm{H}_{2}}$ is the overpotential for the $\mathrm{H}_{2}$ evolution reaction, given by:

$\eta_{\mathrm{H}_{2}}=\phi_{s}-\phi_{e}-E_{0, \mathrm{H}_{2}}$

in which $E_{0, \mathrm{H}_{2}}$ is the formal potential of the reaction.

The total current density in the negative electrode is a sum of the $\mathrm{H}_{2}$ evolution and redox reaction current densities:

$\nabla \cdot \vec{j}=\nabla \cdot \vec{j}_{-}+2 \nabla \cdot \vec{j}_{\mathrm{H}_{2}}=j_{-}+2 j_{\mathrm{H}_{2}}$

This expression is used in Eqs. (20) and (21).

\subsection{Initial and boundary conditions}

At the interfaces between the membrane and porous carbon electrode regions (Fig. 1) the species fluxes (excluding those of the protons and water) and electron flux are considered to be negligibly small. The same condition holds for the species fluxes at all external boundaries except the inlets and outlets:

$\vec{N}_{i} \cdot \vec{n}=0 \quad\left\{\begin{array}{l}x=x_{1}, \quad x=x_{4} \\ x=x_{2}, \quad x=x_{3} \text { (except water/protons) } \\ y=0, \quad y=h \text { (except inlet/outlet) }\end{array}\right.$

$\nabla \phi_{s} \cdot \vec{n}=0 \quad\left\{\begin{array}{l}x=x_{2}, \quad x=x_{3} \\ y=0, y=h\end{array}\right.$

The proton flux at the interfaces between the current collectors and the porous carbon electrode is zero, and similarly at all boundaries external to the membrane:

$-\nabla \cdot\left(\sigma_{e} \nabla \phi_{e}+F A \sum_{i} z_{i} D_{i} \nabla c_{i}\right) \cdot \vec{n}=0 ; \quad x=x_{1}, \quad x=x_{4}$
$-\nabla \phi_{e} \cdot \vec{n}=0 ; \quad y=0, \quad y=h$ (membrane)

A Neumann condition is applied to the liquid pressure at all boundaries of the domain except the inlets and outlets:

$\nabla p \cdot \vec{n}=0$ (except inlets and outlets)

At the inlets, the reactants enter with a prescribed bulk velocity and with concentrations that depend on the pump rate (see Section 3.3):

$\left.\begin{array}{l}c_{i}=c_{i}^{\text {in }}(t) \\ v_{y}=v_{\text {in }}\end{array}\right\} \quad$ Inlets

At the outlets, the liquid pressure is prescribed and the diffusive concentration fluxes are set to zero (fully developed flow conditions):

$$
\left.\begin{array}{l}
\nabla c_{i} \cdot \vec{n}=0 \\
p=p_{\text {out }}
\end{array}\right\} \quad \text { Outlets }
$$

\begin{tabular}{|c|c|c|}
\hline Symbol & Quantity & Value \\
\hline$T$ & Operating temperature & $27^{\circ} \mathrm{C}$ \\
\hline$c_{3}^{0}$ & $\mathrm{~V}(\mathrm{III})$ concentration at inlet $(t=0)$ & $1053 \mathrm{~mol} \mathrm{~m}^{-3}$ \\
\hline$c_{2}^{0}$ & $\mathrm{~V}(\mathrm{II})$ concentration at inlet $(t=0)$ & $27 \mathrm{~mol} \mathrm{~m}^{-3}$ \\
\hline$c_{4}^{0}$ & $\mathrm{~V}(\mathrm{IV})$ concentration at inlet $(t=0)$ & $1053 \mathrm{~mol} \mathrm{~m}^{-3}$ \\
\hline$c_{5}^{0}$ & $\mathrm{~V}(\mathrm{~V})$ concentration at inlet $(t=0)$ & $27 \mathrm{~mol} \mathrm{~m}^{-3}$ \\
\hline$c_{d}^{0}$ & Water concentration at inlets $(t=0)$ & $4.2 \times 10^{3} \mathrm{~mol} \mathrm{~m}^{-3}$ \\
\hline$c_{\mathrm{HSO}^{-}}^{0}$ & Initial $\mathrm{HSO}_{4}^{-}$concentration & $1200 \mathrm{~mol} \mathrm{~m}^{-3}$ \\
\hline$c_{\mathrm{SO}^{2-}}^{0,-}$ & Initial $\mathrm{SO}_{4}{ }^{2-}$ concentration (- ve electrode) & $1607 \mathrm{~mol} \mathrm{~m}^{-3 a}$ \\
\hline$c_{\mathrm{SO}_{4}^{2-}}^{0,4}$ & Initial $\mathrm{SO}_{4}{ }^{2-}$ concentration ( + ve electrode) & $2174 \mathrm{~mol} \mathrm{~m}^{-3 \mathrm{a}}$ \\
\hline$c_{\mathrm{H}^{+}}^{0}$ & Initial $\mathrm{H}^{+}$concentration & $1200 \mathrm{~mol} \mathrm{~m}^{-3}$ \\
\hline$p_{\text {out }, c}$ & Negative electrode outlet pressure & $300 \mathrm{kPa}$ \\
\hline$p_{\text {out }, a}$ & Positive electrode outlet pressure & $300 \mathrm{kPa}$ \\
\hline$Q_{c}$ & Negative electrode volumetric inlet flow rate & $1 \mathrm{mLs}^{-1}$ \\
\hline$Q_{a}$ & Positive electrode volumetric inlet flow rate & $1 \mathrm{mLs}^{-1}$ \\
\hline$I_{\text {appl }}$ & Applied current & $10 \mathrm{~A}$ \\
\hline
\end{tabular}

Table 2

Default initial and boundary values.

a Calculated from the electroneutrality condition (16).

Along the electrode/current collector interfaces, a no-slip condition is enforced on the liquid velocity:

$\vec{u}=0 ; \quad x=0, \quad x=x_{5}$

At the outlet, the gas phase flows outwards with the gas velocity negating the need for a boundary condition. At the inlet, it is assumed that the electrolyte is free of bubbles, yielding the condition:

$\phi_{g}=0 ; \quad y=0$

For the present galvanostatic case the current is assumed to enter or leave uniformly through the current collectors, manifested through the following flux conditions (during charge):

$-\sigma_{\text {coll }} \nabla \phi_{s} \cdot \vec{n}= \begin{cases}-\frac{I_{\mathrm{appl}}}{a} ; & x=0 \\ \frac{I_{\mathrm{appl}}}{a} ; & x=x_{5}\end{cases}$

where $I_{\text {appl }}$ is the current and $a$ is the surface area of the current collector/porous electrode interface.

Consistent initial conditions are prescribed for the concentrations and potentials as follows:

Negative electrode $\left\{\begin{array}{l}c_{i}=c_{i}^{0} \\ \phi_{s}=E_{0,-} \\ \phi_{e}=0\end{array} ; \quad\right.$ Positive electrode $\left\{\begin{array}{l}c_{i}=c_{i}^{0} \\ \phi_{s}=E_{0,+} \\ \phi_{e}=0\end{array}\right.$

\subsection{Numerical details and parameters}

In the experiments, the cell potential difference was measured from the potential difference across the dummy cell, i.e., with conditions pertaining to the outlets. In the simulations, the cell potential difference was measured with respect to the potentials at the intersections between the current collectors and electrodes along the outlet, $y=h$ (see Fig. 1).

The default set of parameter values for the simulations is given in Tables 2-5. These values were used unless otherwise stated. The current collector properties were based on values for stainless steel. Where available, values for Sigratherm GFA5 were used for the porous carbon electrode. The quoted ${ }^{1}$ resistivity of Sigratherm GFA5 is anisotropic, approximately $3.5 \Omega \mathrm{mm}$ in the transverse direction and $2 \Omega \mathrm{mm}$ in the longitudinal direction. These values were averaged to give an isotropic resistivity value. The average

\footnotetext{
1 www.sglcarbon.com.cn/gs/pdf/weichfilz_e.pdf. Last accessed 30 May 2009.
} 
Table 3

Default values of the structural parameters used in the model.

\begin{tabular}{lll}
\hline Symbol & Quantity & Size \\
\hline$h$ & Electrode height & $10 \mathrm{~cm}$ \\
$L_{t}$ & Carbon electrode thickness & $4 \mathrm{~mm}$ \\
$L_{w}$ & Carbon electrode width & $10 \mathrm{~cm}$ \\
$L_{m}$ & Membrane thickness & $180 \mu \mathrm{m}$ \\
$L_{c}$ & Collector thickness & $6 \mathrm{~mm}$ \\
$\epsilon$ & Carbon electrode porosity & $0.68 \mathrm{a}$ \\
$d$ & Carbon electrode fibre diameter & $172 \mu \mathrm{m} \mathrm{[44]}$ \\
$d_{g}$ & H$_{2}$ gas bubble diameter & $50 \mu \mathrm{m}$ \\
$L_{w}$ & Electrode width & $10 \mathrm{~cm}$ \\
$V_{T}$ & Electrolyte volume (half-cell) & $250 \mathrm{~mL}^{-1 \mathrm{~b}}$ \\
$a$ & Specific surface area: electrode & $2 \times 10^{6} \mathrm{~m}^{-1}$ \\
\hline
\end{tabular}

a Measured.

b Estimated.

Table 4

Default values of the constants related to electrochemistry.

\begin{tabular}{|c|c|c|}
\hline Symbol & Quantity & Size \\
\hline$k_{1}$ & Standard rate constant for reaction (1) & $1.75 \times 10^{-7} \mathrm{~m} \mathrm{~s}^{-1}[11]$ \\
\hline$k_{2}$ & Standard rate constant for reaction (2) & $3 \times 10^{-9} \mathrm{~ms}^{-1}[26]$ \\
\hline$j_{0, \mathrm{H}_{2}}$ & $\begin{array}{l}\mathrm{H}_{2} \text { evolution exchange volumetric current } \\
\text { density }\end{array}$ & $1.4 \times 10^{-9} \mathrm{~A} \mathrm{~m}^{-2 \mathrm{a}}$ \\
\hline$\beta_{-}$ & $\begin{array}{l}\text { Cathodic transfer coefficient for reaction } \\
\text { (1) }\end{array}$ & $0.5^{b}$ \\
\hline$\beta_{+}$ & $\begin{array}{l}\text { Cathodic transfer coefficient for reaction } \\
\text { (2) }\end{array}$ & $0.5^{b}$ \\
\hline$\beta_{\mathrm{H}_{2}}$ & Transfer coefficient for reaction (3) & $0.35[28]$ \\
\hline$E_{0,-}^{\prime}$ & Formal potential: V(II)/V(III) & -0.255 V vs. NHE [48] \\
\hline$E_{0,+}^{\prime}$ & Formal potential: $\mathrm{V}(\mathrm{IV}) / \mathrm{V}(\mathrm{V})$ & 1.004 V vs. NHE [48] \\
\hline$c_{f}$ & Fixed charge site (sulfonate) concentration & $1200 \mathrm{~mol} \mathrm{~m}^{-3}[41]$ \\
\hline$z_{f}$ & Charge of fixed (sulfonate) sites & -1 \\
\hline
\end{tabular}

pore diameter of porous carbon foam and felt electrodes is typically in the range $100-800 \mu \mathrm{m}$ [42]. Two reported values for the Sigratherm family of electrodes are $152 \mu \mathrm{m}$ [43] by Vatistas et al. and $172 \mu \mathrm{m}$ [44] by Carta et al.. In the absence of an exact value for GFA5, the value reported by Carta et al. was used.

The rate constant for the reaction at the positive electrode was determined by Gattrel et al. [26], while the rate constant for the negative electrode reaction was derived through a fitting procedure in [11]. Diffusion coefficients for the reactants through the

Table 5

Default values for constants related to the transport of charge and mass.

\begin{tabular}{|c|c|c|}
\hline Symbol & Quantity & Size \\
\hline$D_{2}$ & $\mathrm{~V}$ (II) diffusion coefficient in electrolyte & $2.4 \times 10^{-10} \mathrm{~m}^{2} \mathrm{~s}^{-1}[45]$ \\
\hline$D_{3}$ & V(III) diffusion coefficient in electrolyte & $2.4 \times 10^{-10} \mathrm{~m}^{2} \mathrm{~s}^{-1}[45]$ \\
\hline$D_{4}$ & V(IV) diffusion coefficient in electrolyte & $3.9 \times 10^{-10} \mathrm{~m}^{2} \mathrm{~s}^{-1}[45]$ \\
\hline$D_{5}$ & $\mathrm{~V}(\mathrm{~V})$ diffusion coefficient in electrolyte & $3.9 \times 10^{-10} \mathrm{~m}^{2} \mathrm{~s}^{-1}[45]$ \\
\hline$D_{\mathrm{H}_{2} \mathrm{O}}$ & Water diffusion coefficient in electrolyte & $2.3 \times 10^{-9} \mathrm{~m}^{2} \mathrm{~s}^{-1}[49]$ \\
\hline$D_{w}$ & $\begin{array}{l}\text { Water diffusion coefficient in the } \\
\text { membrane }\end{array}$ & $5.75 \times 10^{-10} \mathrm{~m}^{2} \mathrm{~s}^{-1}[50]$ \\
\hline$D_{\mathrm{H}^{+}}$ & $\begin{array}{l}\text { Proton diffusion coefficient in the } \\
\text { membrane }\end{array}$ & $1.4 \times 10^{-9} \mathrm{~m}^{2} \mathrm{~s}^{-1}[51]$ \\
\hline$D_{\mathrm{HSO}_{4}^{-}}$ & $\begin{array}{l}\mathrm{HSO}_{4}^{-} \text {diffusion coefficient in the } \\
\text { membrane }\end{array}$ & $1.4 \times 10^{-9} \mathrm{~m}^{2} \mathrm{~s}^{-1}[51]$ \\
\hline $\mathrm{D}_{\mathrm{SO}_{4}^{2-}}$ & $\begin{array}{l}\mathrm{SO}_{4}{ }^{2-} \text { diffusion coefficient in the } \\
\text { membrane }\end{array}$ & $1.4 \times 10^{-9} \mathrm{~m}^{2} \mathrm{~s}^{-1}[51]$ \\
\hline$K$ & $\begin{array}{l}\text { Kozeny-Carman constant: porous } \\
\text { electrode }\end{array}$ & $5.55[52]$ \\
\hline$\kappa_{\phi}$ & Electrokinetic permeability: membrane & $1.13 \times 10^{-19} \mathrm{~m}^{2}[51]$ \\
\hline$\kappa_{p}$ & Hydraulic permeability: membrane & $1.58 \times 10^{-18} \mathrm{~m}^{2}[53]$ \\
\hline$\mu_{\mathrm{H}_{2} \mathrm{O}}$ & Water viscosity & $10^{-3} \mathrm{~Pa} \mathrm{~S}$ \\
\hline$\sigma_{f}$ & $\begin{array}{l}\text { Electronic conductivity of porous } \\
\text { electrode }\end{array}$ & $363 \mathrm{~S} \mathrm{~m}^{-1}$ \\
\hline$\sigma_{\text {coll }}$ & Electronic conductivity of collectors & $1000 \mathrm{Sm}^{-1 \mathrm{a}}$ \\
\hline
\end{tabular}

a Estimate. electrolyte were determined by Yamamura et al. [45]. Literature values for the $\mathrm{H}_{2}$ evolution rate on bare carbon electrodes, particularly the Sigratherm family, were found to be scarce. The values of the $\mathrm{H}_{2}$ evolution exchange current density, $j_{0, \mathrm{H}_{2}}$ and the transfer coefficient, $\beta_{\mathrm{H}_{2}}$ were initially taken from [28], for bare reticulated vitreous carbon. The value of $j_{0, \mathrm{H}_{2}}\left(1.4 \times 10^{-2} \mathrm{Acm}^{-2}\right)$, however to lead to non-physical values for the $\mathrm{H}_{2}$ volume fraction, which reached unity in a short period of time in many calculations. In order to achieve reasonable results approximately $10 \%$ for the volume fraction of gas, a value of $j_{0, \mathrm{H}_{2}}=1.4 \times 10^{-5} \mathrm{~A} \mathrm{~cm}^{-2}$ was instead used.

The membrane parameter values were based on Nafion ${ }^{\circledR}$. In particular, the following phenomenological relationship for the diffusion coefficient of water was used [46]:

$D_{w}=4.17 \times 10^{-8} \lambda\left(1+161 e^{-\lambda}\right) \exp \left(-\frac{2436}{T}\right)$ in $\mathrm{m}^{2} \mathrm{~s}^{-1}$

The initial proton concentration was set equal to the fixed charged site concentration in the membrane, $c_{f}$, and the initial concentration of the bisulfate ions $\mathrm{HSO}_{4}{ }^{-}$was assumed to be equal to that of the protons. The initial concentrations of the vanadium species were based on a $5 \%$ initial state of charge. The initial concentration of $\mathrm{SO}_{4}{ }^{2-}$ ions was then determined by the condition of electroneutrality (16). All values are given in Table 2.

The bubble diameter depends on various factors, including the electrolyte, composition, current density and flow rate. A wide range of diameter values has been reported [14,15,47], and the full range is considered in this work: $25-100 \mu \mathrm{m}$.

The cell potential difference can be decomposed into several components, representing the various resistances in the cell:

$E_{\text {cell }}=E_{-}-E_{+}-\sum_{j}\left|\eta_{j}\right|-I_{\text {app }} \sum_{k} R_{k}$

where the $\eta_{j}$ are overpotentials due to resistances in charge transfer, mass transfer, leaks and imperfect electrical contact between the components; and the $R_{k}$ are charge transport (ohmic) resistances. The majority of the components in Eq. (47) were explicitly included in the model but in order to match the experimental results, it was found necessary to include an additional lumped resistance. The fitting procedure in the base case yielded a value of $131 \mathrm{mV}$. All cell potential difference curves were shifted vertically downwards by this value. The origin of this lumped parameter is likely to be contact resistance, although mass-transfer resistance in the tubing, stagnant regions in the electrode and leaks could also play a role. Relatively minor differences between the simulation and experimental results were still seen, and these can be attributed to the same causes. The primary aim, however, is to capture the correct qualitative trends with the fewest fitting parameters.

The system of equations was solved using the COMSOL Multiphysics ${ }^{\circledR}$ package, with a combination of the convection-diffusion, general-form and ODE options (for the initial concentrations). The package is based on the finite-element method; a quadratic basis was used in all of the simulations, together with a minimum of 2548 elements and a maximum of 7256 elements. The relative error tolerance was set to $1 \times 10^{-6}$. The base-case calculation (a charge-discharge of $63 \mathrm{~min}$ with $Q=1 \mathrm{~mL} \mathrm{~s}^{-1}, \quad c_{3}^{0}=c_{4}^{0}=1080 \mathrm{~mol} \mathrm{~m}^{-3}, \quad T=273 \mathrm{~K}, \quad d_{g}=50 \mu \mathrm{m}$, $I_{\mathrm{appl}}=10 \mathrm{~A}$ ) took $27 \mathrm{~min}$ on an Athlon $4600+$ dual core, 64-bit desktop with $4 \mathrm{~Gb}$ RAM. This relatively long simulation time can be attributed to the large number of elements required to obtain converged solutions with acceptable levels of accuracy. 


\section{Results and discussion}

All calculations were performed to an equivalent state of charge SOC, estimated from the residual V(III) concentration:

$1-\frac{c_{3, \mathrm{av}}}{c_{3}^{0}}$

where zero corresponds to no charge and unity to a full charge. The quantity $c_{3, \text { av }}$ is the volume-averaged V(III) concentration in the negative half-cell, including both the electrode and reservoir volumes.

Experiments were carried out at two different vanadium concentrations and mean linear flow velocities. For each case, the SOC value at the end of the charging period was estimated from simulation to be 0.794 based on the experimental charge time for $c_{3}^{0}=c_{4}^{0}=1080 \mathrm{~mol} \mathrm{~m}^{-3}$ (in the base case simulation, the experimental charge time was used and the SOC, as defined above, was measured). At the end of the charge period, 2 min of operation at zero current followed by discharge were simulated in each calculation. The voltage and coulombic efficiencies for a constant-current charge/discharge process are defined as:

$\% \xi_{v}=\frac{\int_{0}^{t_{c}} E_{\text {cell }} \mathrm{d} t}{\int_{t_{c}}^{t_{d}} E_{\text {cell }} \mathrm{d} t} \times 100$

and

$\% \xi_{c}=\frac{t_{d}}{t_{c}} \times 100$

respectively, where $t_{c}$ is the time to charge and $t_{d}$ is the time to discharge.
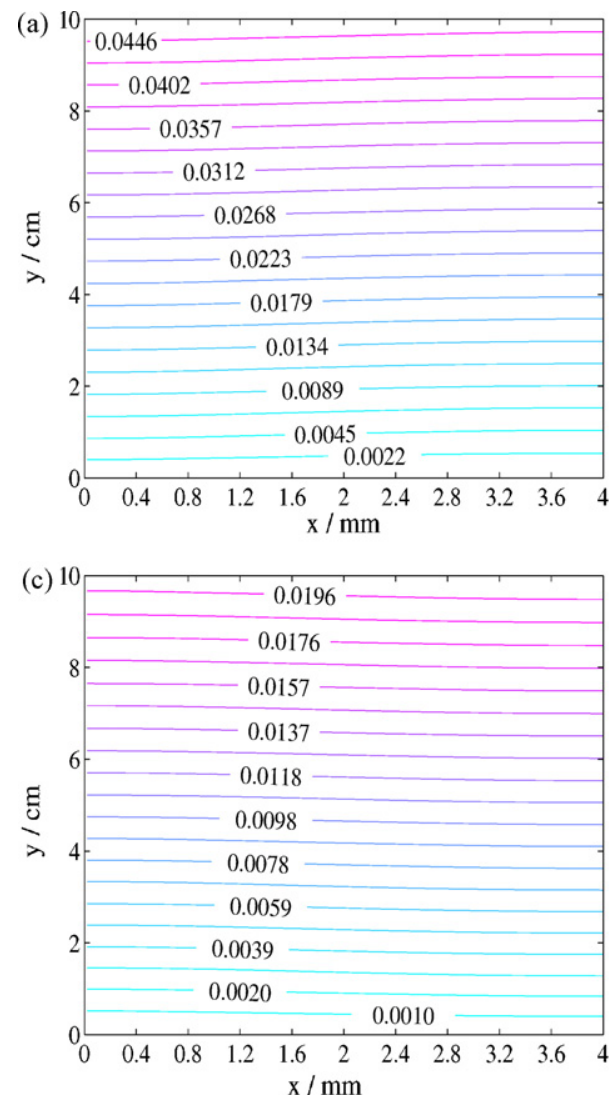

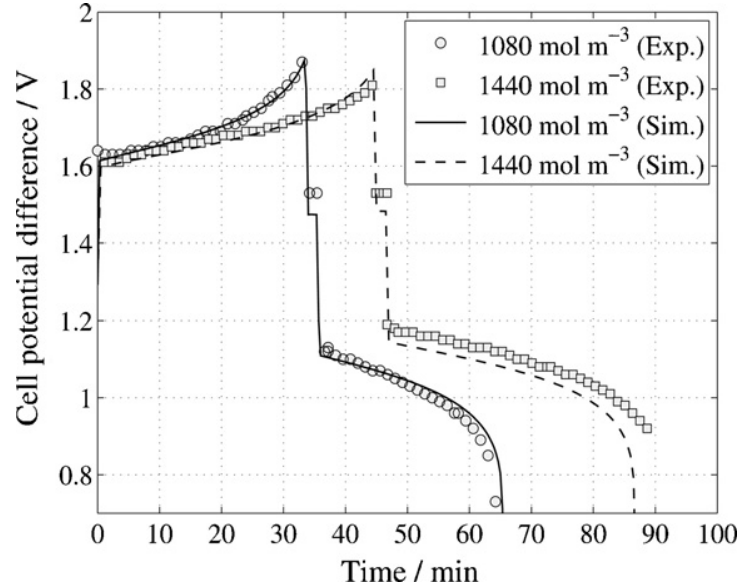

Fig. 2. A comparison between simulated and experimentally obtained cell potential difference, $E_{\text {cell }}$ curves during charge/discharge for two different concentrations, $c_{3}^{0}=c_{4}^{0}=1080 \mathrm{~mol} \mathrm{~m}^{-3}$ and $c_{3}^{0}=c_{4}^{0}=1440 \mathrm{~mol} \mathrm{~m}^{-3} ; I_{\text {appl }}=10 \mathrm{~A}, Q=1 \mathrm{~mL} \mathrm{~s}^{-1}$ and $d_{g}=50 \mu \mathrm{m}$ in both cases. The other parameter values are given in Tables 2-5. For both concentrations, $S O C=0.794$ at the end of charge: $t=2017 \mathrm{~s}$ for $c_{3}^{0}=$ $1080 \mathrm{~mol} \mathrm{~m}^{-3}$ and $t=2687 \mathrm{~s}$ for $c_{3}^{0}=1440 \mathrm{~mol} \mathrm{~m}^{-3}$.

\subsection{Validation and effect of hydrogen evolution}

Fig. 2 shows a comparison between the simulated and experimentally obtained cell potential difference, $E_{\text {cell }}$ curves during charge/discharge for two different concentrations, $c_{3}^{0}=c_{4}^{0}=$ $1080 \mathrm{~mol} \mathrm{~m}^{-3}$ and $c_{3}^{0}=c_{4}^{0}=1440 \mathrm{~mol} \mathrm{~m}^{-3}$, with an applied current $I_{\text {appl }}=10 \mathrm{~A}$, a mean linear flow rate $Q=1 \mathrm{~mL} \mathrm{~s}^{-1}$ and a bubble diameter $d_{g}=50 \mu \mathrm{m}$ in both cases. The other parameter values
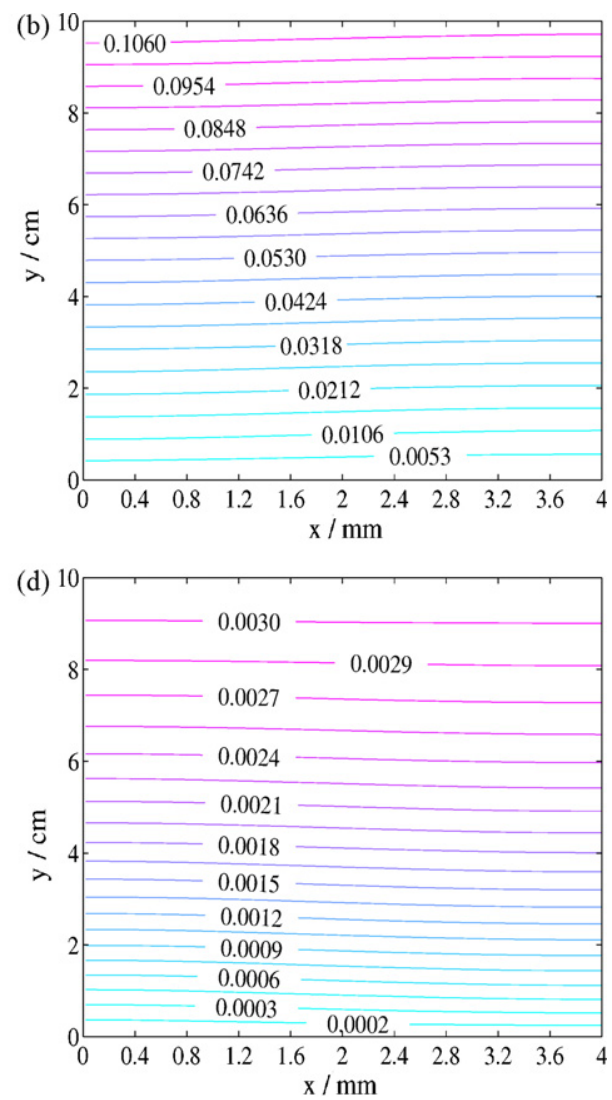

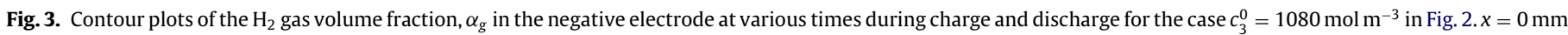

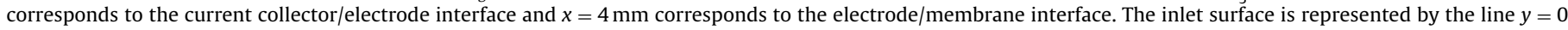
and the outlet by $y=10 \mathrm{~cm}$. (a) $t=1009 \mathrm{~s}$; (b) $t=2017 \mathrm{~s}$; (c) $t=3000 \mathrm{~s}$; (d) $t=3900 \mathrm{~s}$. 
are given in Tables 2-5. The model captures the trends extremely well. The discrepancies between the experimental and simulation results were discussed in Section 3.6. Both sets of results show increased efficiencies for an increased concentration. At the lower concentration, $\xi_{v}=59.7 \%$ and at the higher concentration, $\xi_{v}=61.5 \%$, while the coulombic efficiencies are $87.8 \%$ and $90.1 \%$ for the lower and higher concentrations, respectively. The latter two compare favourably with the experimental values of $85.1 \%$ and $93.1 \%$, respectively.

Contour plots of the $\mathrm{H}_{2}$ gas volume fraction, $\alpha_{g}$ at various times during charge and discharge for the case $c_{3}^{0}=1080 \mathrm{~mol} \mathrm{~m}^{-3}$ are shown in Fig. 2 . In these plots, $x=0 \mathrm{~mm}$ corresponds to $x_{1}$ in Fig. 1 , the current collector/negative electrode interface and $x=4 \mathrm{~mm}$ corresponds to $x_{2}$, the negative electrode/membrane interface. The inlet surface is represented by the line $y=0$ and the outlet by $y=10 \mathrm{~cm}$. During charge (Fig. 3(a) $1009 \mathrm{~s}$ and (b) $2017 \mathrm{~s}$ ), the volume fraction of $\mathrm{H}_{2}$ increases as the height above the inlet surface increases along any vertical line. At the inlet, a zero volume fraction is maintained through the boundary condition, which represents inflow from a reservoir free of bubbles. It is worth noting that at the end of discharge (Fig. 3(d)), the $\mathrm{H}_{2}$ has not entirely disappeared from the electrode, although the volume remaining is small.

In the $x$ (horizontal) direction, the degree of variation in $\alpha_{g}$ is minimal, despite substantial variations in the $\mathrm{H}_{2}$ volumetric current density, $2 j_{\mathrm{H}_{2}}$, as evidenced in Fig. 4 , which shows the $\mathrm{H}_{2}$ volumetric current density (in $\mathrm{A} \mathrm{cm}^{-3}$ ) and overpotential $\eta_{\mathrm{H}_{2}}$ (in $\mathrm{mV}$ ) in the negative electrode during charge for the case $c_{3}^{0}=1080 \mathrm{~mol} \mathrm{~m}^{-3}$ (Fig. 4(a), (c) $1009 \mathrm{~s}$ and (b), (d) $2017 \mathrm{~s}$ ). Also evident from these plots is that the $\mathrm{H}_{2}$ volumetric current density and the $\mathrm{H}_{2}$ overpotential are closely linked, both sets of contours resembling a similar pattern during charge. Maxima in both are attained at the inter- section between the outlet and the current collector, $y=10 \mathrm{~cm}$, $x=0 \mathrm{~mm}$, and the minima in both occur at the intersection between the membrane and the inlet, $y=0 \mathrm{~cm}$ and $x=4 \mathrm{~mm}$. The $\mathrm{H}_{2}$ current is controlled by the overpotential $\eta_{\mathrm{H}_{2}}$, which is controlled primarily by the electronic potential, $\phi_{S}$ and the open-circuit potential, $E_{0,-}$.

The effect of $\mathrm{H}_{2}$ evolution on the charge/discharge behaviour can be seen in Fig. 5, which show the charge/discharge curve for $c_{3}^{0}=$ $c_{4}^{0}=1080 \mathrm{~mol} \mathrm{~m}^{-3}$ both with and without $\mathrm{H}_{2}$ evolution included in the simulation (charge for $2017 \mathrm{~s}$ under $10 \mathrm{~A}$ followed by $0 \mathrm{~A}$ for $120 \mathrm{~s}$ before discharge at $10 \mathrm{~A}$ ). There are noticeable differences both in the cell potential difference attained at the end of charge and in the times to discharge. For the calculations in Fig. 5, the voltage efficiency is $59.7 \%$ with evolution and $60 \%$ without evolution. The difference between the coulombic efficiencies is more marked: $87.8 \%$ with evolution and $95.9 \%$ without evolution. Fig. 6 (a) and (b) shows the total volumetric current density (in $\mathrm{A} \mathrm{cm}^{-3}$ ) at $t=1900 \mathrm{~s}$, that is, (a) $j=j_{-}+2 j_{\mathrm{H}_{2}}$ with $\mathrm{H}_{2}$ evolution included, and (b) $j=j_{-}$ without $\mathrm{H}_{2}$ evolution included (see Eq. (35) and the corresponding text). In both cases, the maximum occurs at the intersection between the inlet and the current collector, $y=0 \mathrm{~cm}$ and $x=0 \mathrm{~mm}$. With $\mathrm{H}_{2}$ evolution included, the total volumetric current density is lowered. The evolution of the gas bubbles lowers $j_{-}$by a factor of $\alpha_{g}$, which has a maximum of approximately 0.1 according to Fig. 3(b). This reduction is not balanced by the $\mathrm{H}_{2}$ evolution volumetric current density, $2 j_{\mathrm{H}_{2}}$ in the vicinity of the current collector/electrode interface (Fig. 4 (b) indicates that $2 j_{\mathrm{H}_{2}}$ is considerably smaller than $\left.j_{-}\right)$. The corresponding profiles of the overpotential $\eta_{-}$are given in Fig. 6(c) and (d) (in mV). Markedly lower values are attained in the case with no $\mathrm{H}_{2}$ evolution, consistent with the higher values of the total volumetric current density. The minimum overpotential value with $\mathrm{H}_{2}$ evolution included occurs at $x=0 \mathrm{~mm}, y=0 \mathrm{~cm}$, whereas
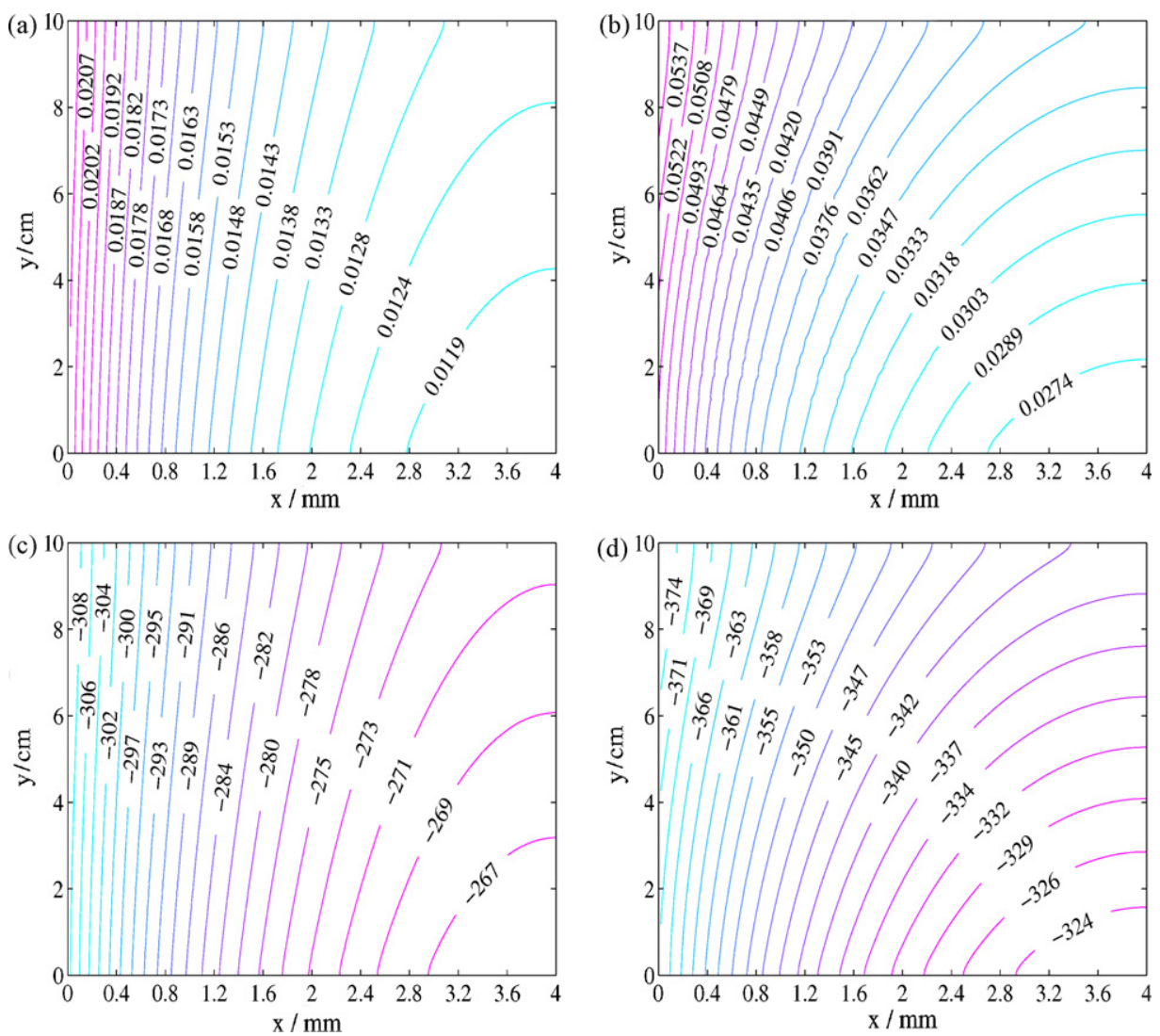

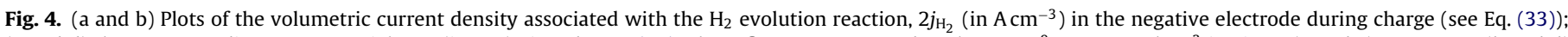

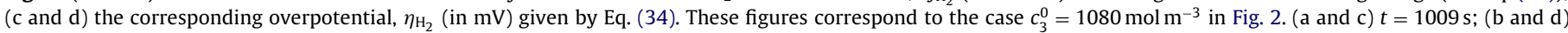
$t=2017 \mathrm{~s}$. 

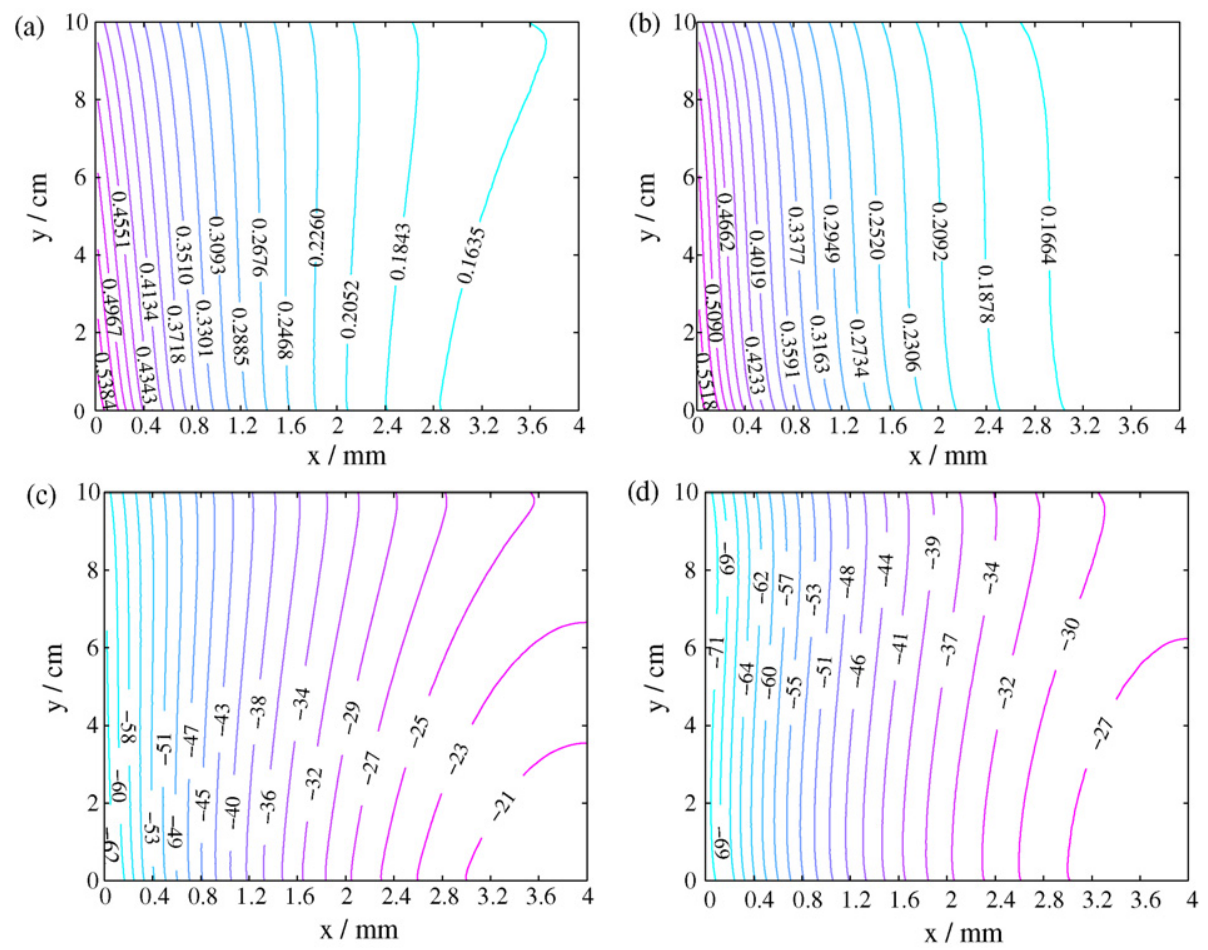

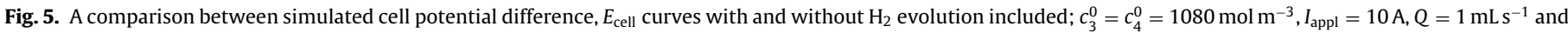

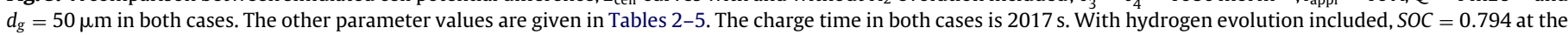
end of charge and without hydrogen evolution, $S O C=0.854$.
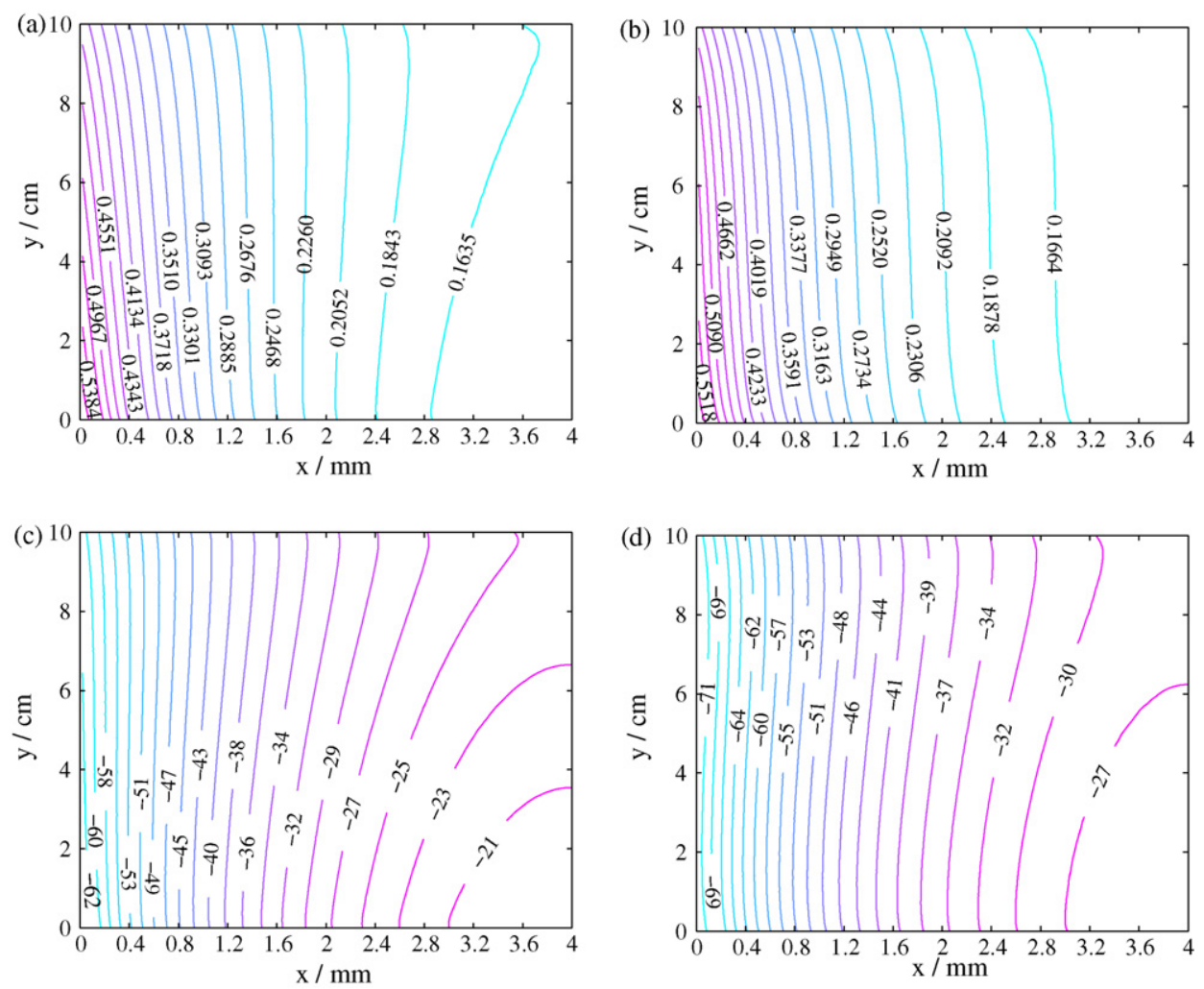

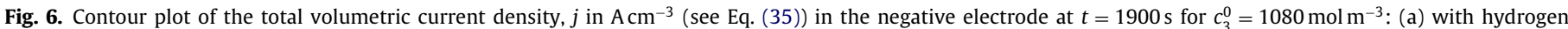

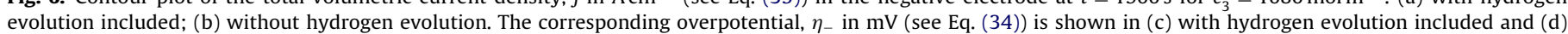

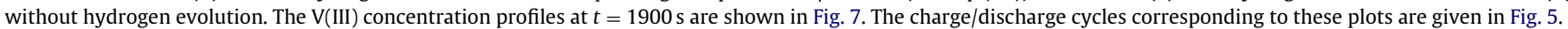


the minimum value without $\mathrm{H}_{2}$ evolution included yields a minimum at around $x=0 \mathrm{~mm}, y=8 \mathrm{~cm}$. Up to a time of $t \approx 1500 \mathrm{~s}$, the minimum is attained at $x=0 \mathrm{~mm}, y=0 \mathrm{~cm}$, as in the case with $\mathrm{H}_{2}$ evolution. Beyond this time, mass transport effects become significant and the open-circuit potential, $E_{0,-}$, which decreases along a vertical line approaching the outlet, decreases more rapidly with time in a region close to the inlet. Simultaneously, the electronic potential, which decreases along any vertical line as the outlet is approached and along any horizontal line as the current collector is approached, also decreases. The net result is that the overpotential minimum is attained above the inlet surface along the current collector/electrode interface.

For the case without $\mathrm{H}_{2}$ evolution included, the higher volumetric current density at a given time leads to a faster depletion of the V(III) reactant in the negative electrode, as seen in Fig. 7, which shows the $\mathrm{V}(\mathrm{III})$ concentration profiles at $t=1900 \mathrm{~s}$ for the two cases (with and without $\mathrm{H}_{2}$ evolution) in Fig. 5. In turn, the overpotentials rise more rapidly to maintain the applied current in the mass-transport limited regime. At the same charge time, $t=2017 \mathrm{~s}$, the concentration of $\mathrm{V}(\mathrm{II})$ is, therefore, higher in the case without evolution; with hydrogen evolution included, $S O C=0.794$ at the end of charge and without hydrogen evolution included, $S O C=0.854$ at the end of charge. This leads to a
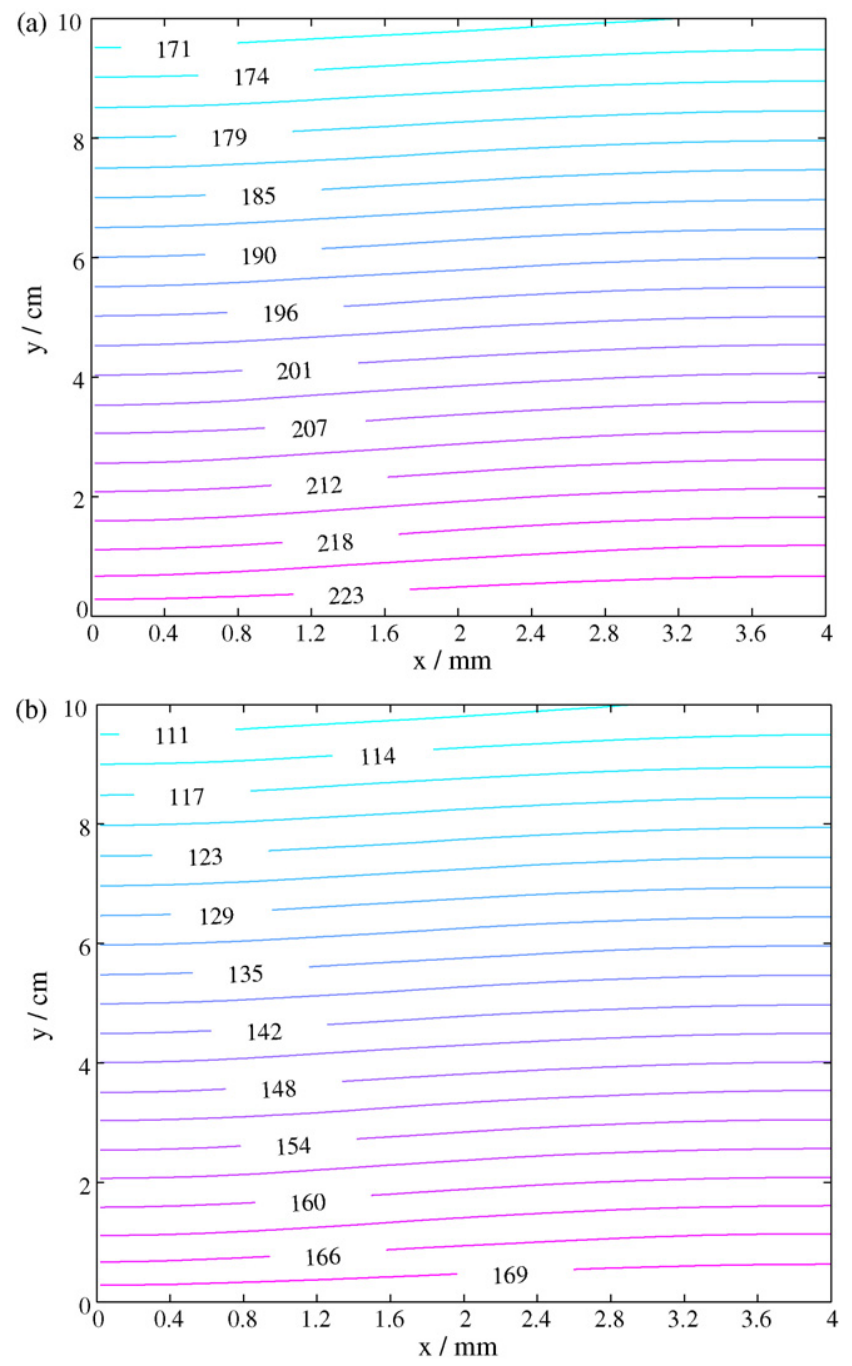

Fig. 7. (a) The $\mathrm{V}$ (III) concentration (in $\mathrm{mol} \mathrm{m}^{-3}$ ) in the negative electrode at $t=$ $1900 \mathrm{~s}$ with $c_{3}^{0}=1080 \mathrm{~mol} \mathrm{~m}^{-3}$ and $\mathrm{H}_{2}$ evolution included; (b) the equivalent plot without $\mathrm{H}_{2}$ evolution. The corresponding potential and volumetric current density profiles are given in Fig. 6 and the charge/discharge curves in Fig. 5. longer discharge time and, consequently, a higher coulombic efficiency.

Fig. 8 shows the evolution of the vertical $(y)$ component of the gas velocity, $\vec{u}_{g} \cdot \vec{e}_{y}$ (in $\mathrm{mm} \mathrm{s}^{-1}$ ) during the charge/discharge process for the case $c_{3}^{0}=c_{4}^{0}=1080 \mathrm{~mol} \mathrm{~m}^{-3}$ in Fig. 2 . The gas velocity in the horizontal direction was three orders of magnitude slower as a result of the convection dominated flow of the electrolyte in the $y$ direction. At the end of charge (Fig. 8(b)), the bubble velocity is approximately $17 \%$ higher than the liquid velocity at the outlet, which is shown in Fig. 9(a); the gas bubbles are carried with the electrolyte vertically upwards and, moreover, are accelerated by a velocity, $\vec{u}_{\text {slip }}$, given in Eq. (12), by buoyancy forces acting in opposition to the viscous drag forces. As with the gas volume fraction, the gas velocity increases along any vertical line from the inlet to the outlet. During charge, the maximum in the gas velocity is attained at the outlet $/$ membrane interface, $y=10 \mathrm{~cm}, x=4 \mathrm{~mm}$, and during discharge it is attained at the outlet/current collector interface, $y=10 \mathrm{~cm}, x=0 \mathrm{~mm}$. During the charge phase, there is a decrease in the gas velocity along any horizontal line from the membrane to the current collector, as a result of the decrease in the liquid velocity in the same direction. This can be seen from Fig. 9, which shows the two contributions to the $y$ component of the gas velocity, the $y$ components of the liquid and slip velocities, at the end of charge (in $\mathrm{mm} \mathrm{s}^{-1}$ ). The $y$ component of the liquid velocity, which has an initial/inlet value of $3.57 \mathrm{~mm} \mathrm{~s}^{-1}$, varies by up to $5 \%$ in the $x$ direction, with lower values towards the current collector surface where the gas volume fraction is higher. During discharge, the liquid velocity (not shown) increases as the current collector is approached from the membrane surface along any horizontal line, which results in a increase in the gas velocity in the same direction (Fig. 8(c) and (d)).

The increased gas velocity in the vertically upward direction and the decreased liquid velocity in the horizontal direction as the current collector is approached are due to the increase in the gas volume fraction, which leads to an increased slip velocity, $\vec{u}_{\text {slip }}$ given by Eq. (12), with the pressure gradient given by Eq. (8). As the gas volume fraction, $\alpha_{g}$ increases, the Kozeny-Carman factor in the relative permeability in Eq. (8) decreases, resulting in a lower liquid velocity, given by Eq. (6), and a higher value of $\nabla p$; the reduced volume of liquid lowers the permeability and increases pressure gradients. To demonstrate this, consider the following one-dimensional boundary value problem:

$$
\begin{array}{ll}
-\frac{\mathrm{d}}{\mathrm{d} y}\left(\frac{d_{f}^{2}}{K \mu_{l}} \frac{\epsilon^{3}\left(1-\alpha_{g}\right)^{3}}{\left(1-\epsilon\left(1-\alpha_{g}\right)\right)^{2}} \frac{\mathrm{d} p}{\mathrm{~d} y}\right)=0 ; & 0<y<h \\
-\frac{d_{f}^{2}}{K \mu_{l}} \frac{\epsilon^{3}\left(1-\alpha_{g}\right)^{3}}{\left(1-\epsilon\left(1-\alpha_{g}\right)\right)^{2}} \frac{\mathrm{d} p}{\mathrm{~d} y}=v_{\text {in }} ; & y=0 \\
p=p_{\text {out }} ; & y=h
\end{array}
$$

with a constant value of $\alpha_{g}$. Integrating the first of these equations and applying the boundary condition at $y=0$, leads to an expression for $\mathrm{d} p / \mathrm{d} y$ :

$$
\frac{\mathrm{d} p}{\mathrm{~d} y}=-v_{\mathrm{in}} \frac{K \mu_{l}\left(1-\epsilon\left(1-\alpha_{g}\right)\right)^{2}}{d_{f}^{2} \epsilon^{3}\left(1-\alpha_{g}\right)^{3}}
$$

which increases as $\alpha_{g}$ increases. This analysis indicates that the slip velocity, which is directly proportional to $\nabla p$, with a constant of proportionality $d_{b}^{2} /\left(18 \mu_{l}\right)$, increases as $\alpha_{g}$ increases, i.e., in the presence of a higher concentration of bubbles.

\subsection{Mean linear flow rate effects}

Fig. 10 compares simulated and experimentally obtained cell potential difference $E_{\text {cell }}$ curves during charge/discharge at the flow rates $Q=1 \mathrm{~mL} \mathrm{~s}^{-1}$ (same as Fig. 2) and $Q=3 \mathrm{~mL} \mathrm{~s}^{-1}$, with $c_{3}^{0}=c_{4}^{0}=$ 

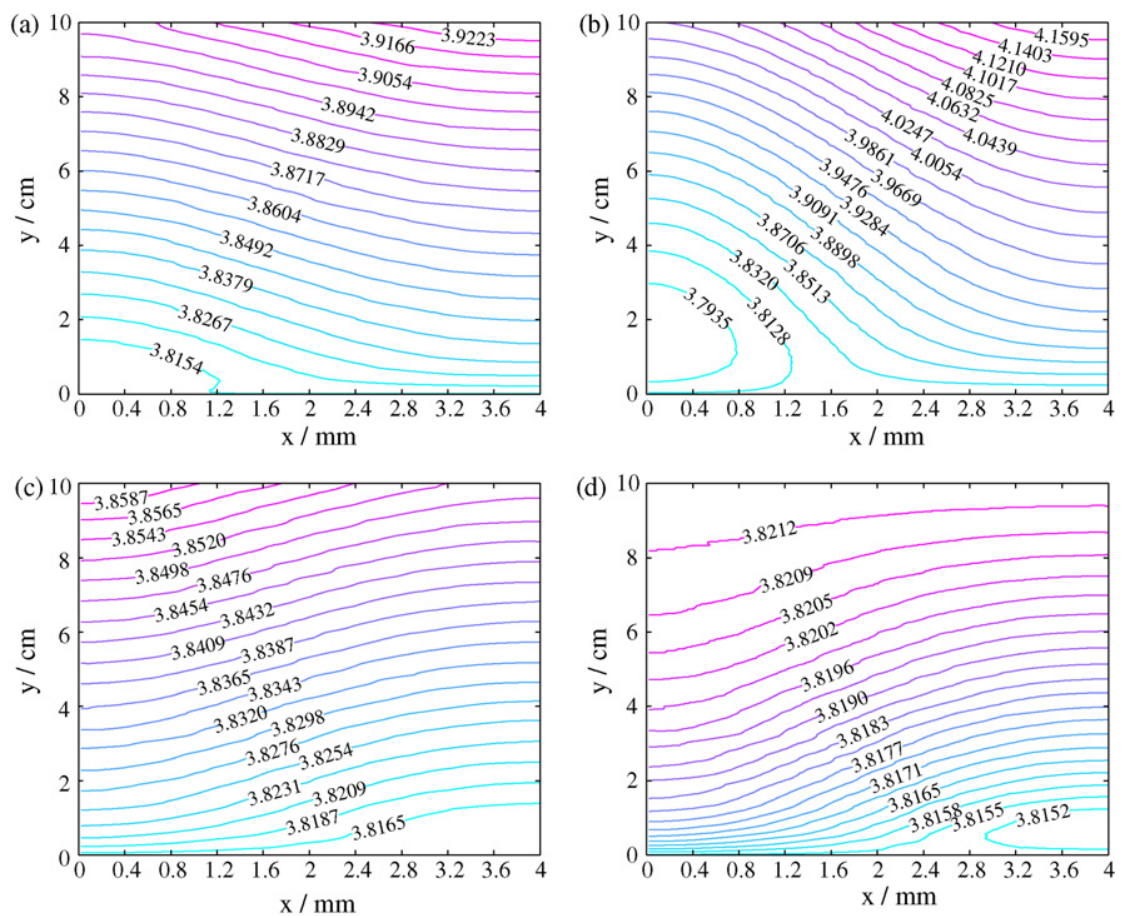

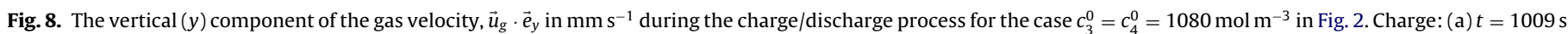
and (b) $t=2017 \mathrm{~s}$; discharge: (c) $t=3000 \mathrm{~s}$ and (d) $t=3900 \mathrm{~s}$.
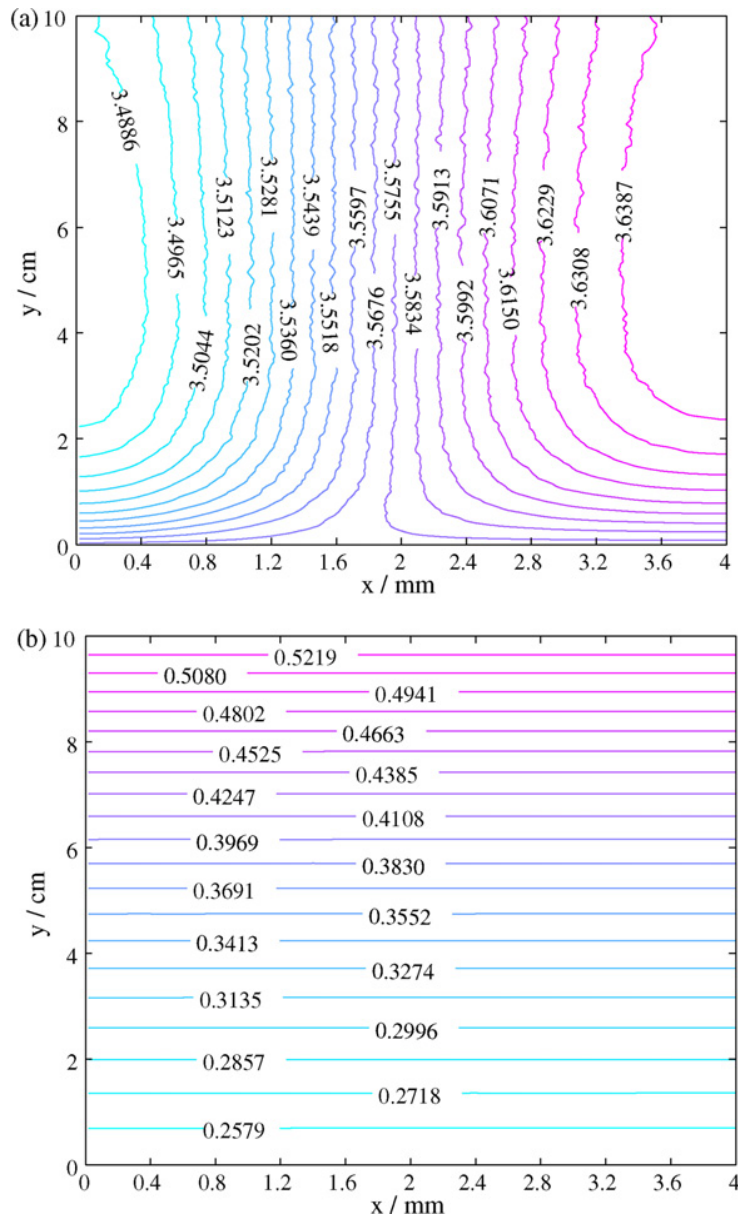

Fig. 9. (a) The $y$ components of the liquid velocity, $\vec{u}_{l} \cdot \vec{e}_{y}$ in $\mathrm{mm} \mathrm{s}^{-1}$ and (b) the $y$ component of the slip velocity, $\vec{u}_{\text {slip }} \cdot \vec{e}_{y}$ in $\mathrm{mm} \mathrm{s}^{-1}$ at the end of charge ( $t=2017 \mathrm{~s}$ ) in the case $c_{3}^{0}=c_{4}^{0}=1080 \mathrm{~mol} \mathrm{~m}^{-3}$ in Fig. 2 .
$1080 \mathrm{~mol} \mathrm{~m}^{-3}$, an applied current $I_{\mathrm{appl}}=10 \mathrm{~A}$ and a bubble diameter $d_{g}=50 \mu \mathrm{m}$. The other parameter values are as in Tables 2-5. The trend is well captured, particularly the increased coulombic efficiency as the flow rate is increased. The simulated values for the coulombic efficiency are $87.8 \%$ and $91.7 \%$ for $Q=1 \mathrm{~mL} \mathrm{~s}^{-1}$ and $Q=3 \mathrm{~mL} \mathrm{~s}^{-1}$, respectively, while the experimental values are $85.1 \%$ and $92.9 \%$, respectively. In agreement with the experimental curves, the cell potential difference at the higher flow rate is slightly lower during charge and the charge time (to the equivalent $S O C$ ) is slightly longer: 2028 s compared to 2017 s. During discharge, the cell potential difference for $Q=3 \mathrm{mLs}^{-1}$ is slightly higher at any given time. The reason for this behaviour is the greater uniformity of the reactants for the higher flow rate (at the equivalent $S O C$ ), as discussed in detail elsewhere [11].

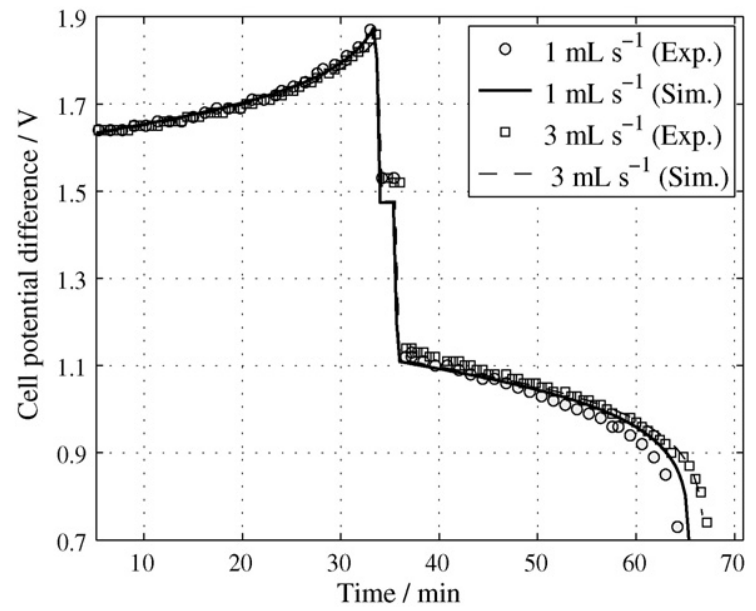

Fig. 10. Simulated and experimentally obtained cell potential difference, $E_{\text {cell }}$ curves during charge/discharge at two flow rates, $Q=1 \mathrm{~mL} \mathrm{~s}^{-1}$ and $Q=3 \mathrm{~mL} \mathrm{~s}^{-1} ; c_{3}^{0}=c_{4}^{0}=$ $1080 \mathrm{~mol} \mathrm{~m}^{-3}, I_{\mathrm{appl}}=10 \mathrm{~A}$ and $d_{g}=50 \mu \mathrm{m}$ in both cases. The other parameter values are given in Tables $2-5$. For both flow rates, $S O C=0.794$ at the end of charge: $t=$ $2017 \mathrm{~s}$ for $Q=1 \mathrm{~mL} \mathrm{~s}^{-1}$ and $t=2028 \mathrm{~s}$ for $Q=3 \mathrm{~mL} \mathrm{~s}^{-1}$. 
Plots of the gas volume fraction, $\alpha_{g}$ and the $y$ component of the gas velocity, $\vec{u}_{g} \cdot \vec{e}_{y}$ (in $\mathrm{mm} \mathrm{s}^{-1}$ ) at the end of charge, $t=2028 \mathrm{~s}$, in the case with $Q=3 \mathrm{mLs}^{-1}$ are given in Fig. 11. The maximum in the gas volume fraction, attained at $x=4 \mathrm{~mm}, y=10 \mathrm{~cm}$, is a factor of approximately 3 lower than the maximum attained for $Q=1 \mathrm{mLs}^{-1}$ (Fig. $3(\mathrm{~b})$ ) at the equivalent SOC. The maximum in the $y$ component of the gas velocity is approximately $10 \%$ greater than the initial liquid velocity. At the lower flow rate, the equivalent difference is approximately $17 \%$ (Fig. 8 (b)). There appears to be a linear relationship between the gas volume fraction and the reciprocal of the flow rate. The lower gas volume fraction leads to a smaller departure of the gas velocity from the liquid velocity, i.e. a lower the slip velocity, as demonstrated in the analysis above.

Fig. 12 shows the distribution of the volumetric $\mathrm{H}_{2}$ evolution current density, $2 j_{\mathrm{H}_{2}}$ (in $\mathrm{Acm}^{-3}$ ) and the overpotential, $\eta_{\mathrm{H}_{2}}$ (in $\mathrm{mV})$ at the end of charge $(t=2028 \mathrm{~s})$ in the case $Q=3 \mathrm{~mL} \mathrm{~s}^{-1}$ in Fig. 10. The higher flow rate leads to a more even distribution of reactant and, consequently, higher (smaller in magnitude) overpotential values. Thus, the $\mathrm{H}_{2}$ evolution rate in the negative electrode is slightly lower than the equivalent rate in Fig. 4(b), which shows $2 j_{\mathrm{H}_{2}}$ for $Q=1 \mathrm{~mL} \mathrm{~s}^{-1}$. The overpotential values are slightly higher than the equivalent overpotential values in Fig. 4(d). The lower gas volume fraction at $Q=3 \mathrm{~mL} \mathrm{~s}^{-1}$ is, however, due primarily to the increased rate at which the electrolyte is moved through the electrode; the flow is convection dominated in the $y$ direction.
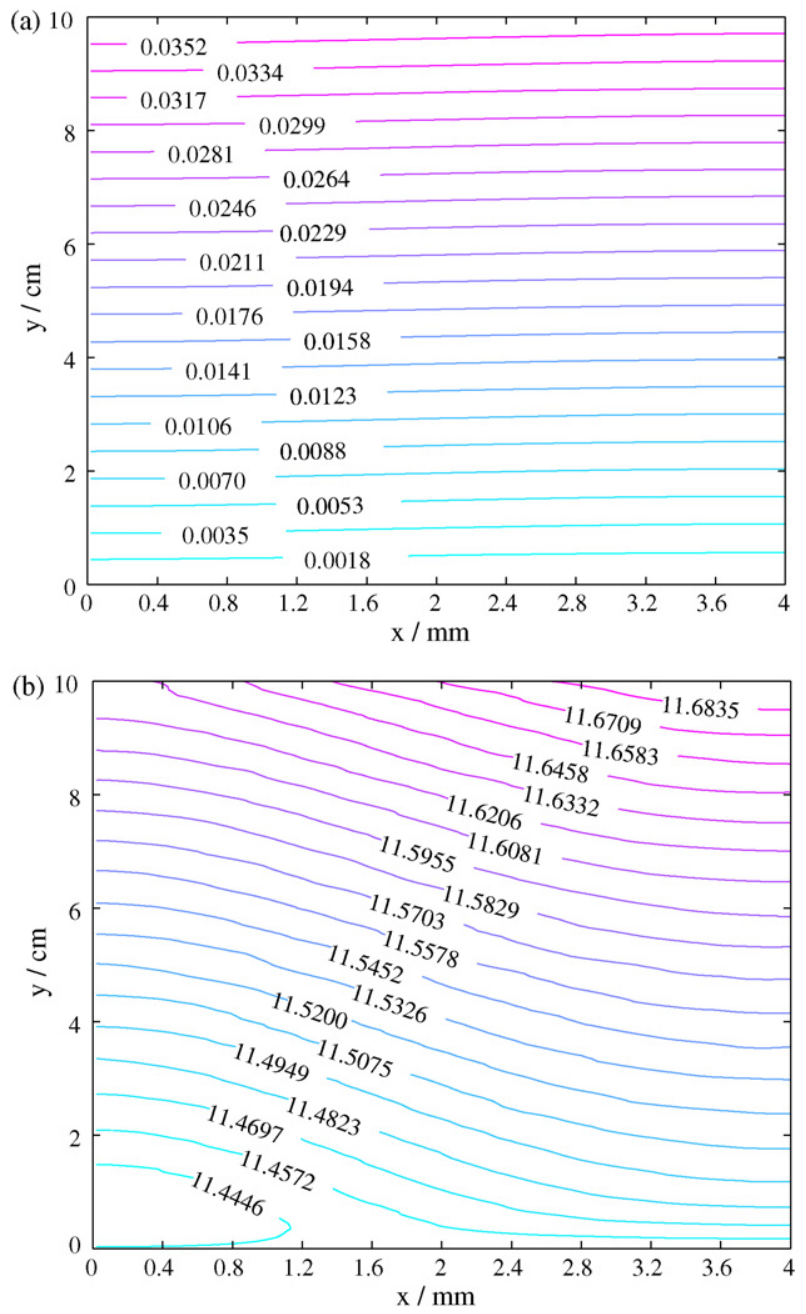

Fig. 11. (a) Distribution of the gas volume fraction, $\alpha_{g}$ and (b) the $y$ component of the gas velocity, $\vec{u}_{g} \cdot \vec{e}_{y}$ in $\mathrm{mm} \mathrm{s}^{-1}$ at the end of charge $(t=2028 \mathrm{~s})$ in the case $Q=3 \mathrm{~mL} \mathrm{~s}^{-1}$ in Fig. 10 .
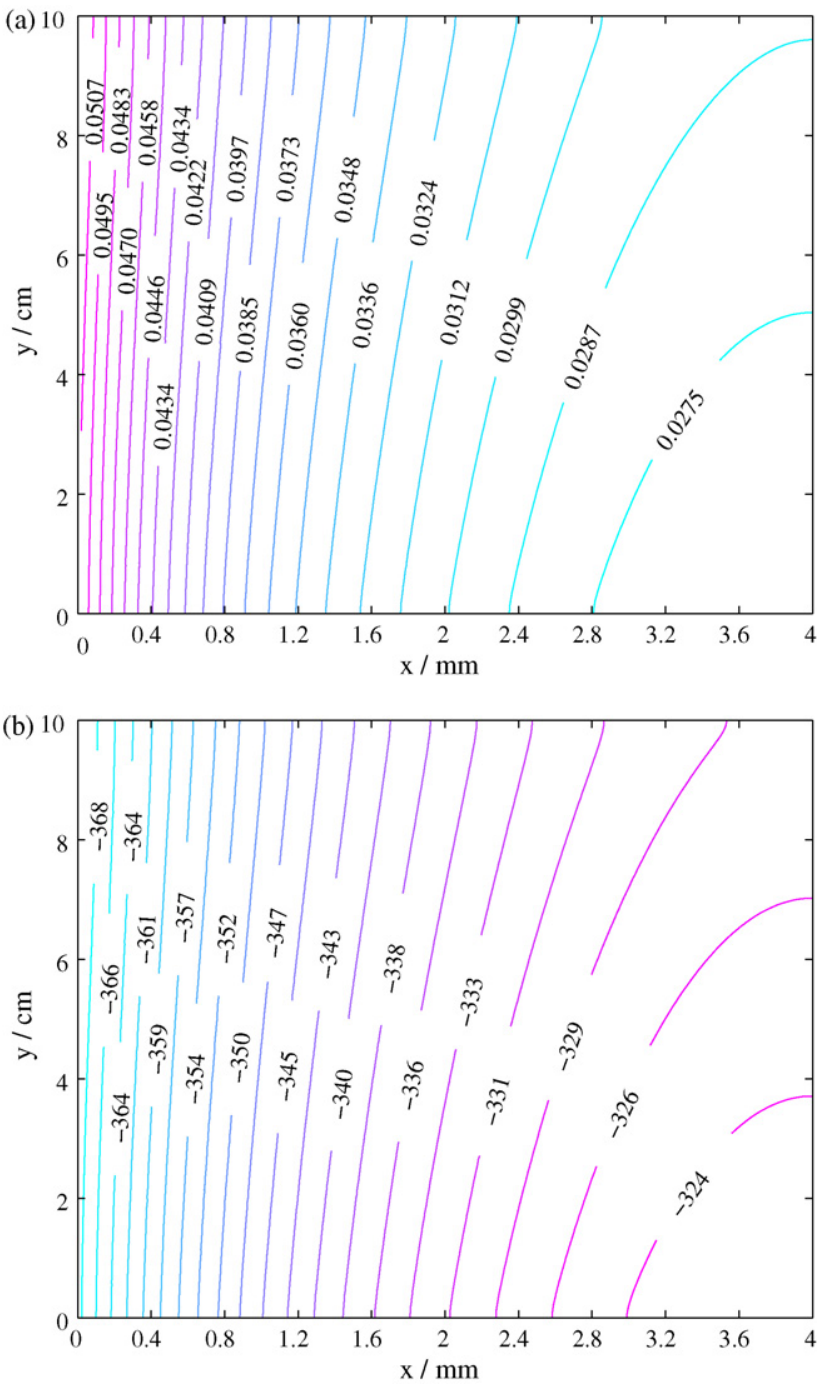

Fig. 12. (a) Distribution of the volumetric $\mathrm{H}_{2}$ evolution current density, $2 j_{\mathrm{H}_{2}}$ in $\mathrm{Acm}^{-3}$ and (b) the overpotential, $\eta_{\mathrm{H}_{2}}$ in $\mathrm{mV}$ at the end of charge $(t=2028 \mathrm{~s})$ in the case $Q=3 \mathrm{mLs}^{-1}$ in Fig. 10 .

\subsection{Applied current effects}

Simulated cell potential difference, $E_{\text {cell }}$ curves during charge/discharge at two applied currents, $I_{\text {appl }}=10 \mathrm{~A}$ (same as Fig. 2) and $I_{\text {appl }}=15 \mathrm{~A}$, are shown in Fig. 13. In these calculations, $c_{3}^{0}=c_{4}^{0}=1080 \mathrm{~mol} \mathrm{~m}^{-3}, Q=1 \mathrm{~mL} \mathrm{~s}^{-1}$ and $d_{g}=50 \mu \mathrm{m}$. The other parameter values are given in Tables $2-5$. The charge times are chosen to give the same SOC at the end of the charging period: $t=2017$ for $I_{\mathrm{appl}}=10$ and $t=1321 \mathrm{~s}$ for $I_{\mathrm{appl}}=15$. The efficiencies are lowered by the increased current. The voltage efficiency drops from $\xi_{v}=59.7 \%$ to $51.8 \%$, while the coulombic efficiency experiences only a mild drop from $\xi_{c}=87.8 \%$ to $86.2 \%$.

Fig. 14 shows the distribution of the gas volume fraction, $\alpha_{g}$ and the $y$ component of the gas velocity, $\vec{u}_{g} \cdot \vec{e}_{y}$ (in $\mathrm{mm} \mathrm{s}^{-1}$ ) at the end of charge in the case with $I_{\mathrm{appl}}=15 \mathrm{~A}$ in Fig. 13. These figures are to be compared with Figs. 2(b) and 8(b), respectively, for the case $I_{\text {appl }}=15 \mathrm{~A}$. The maximum in the gas volume fraction, attained at $y=10 \mathrm{~cm}, x=0 \mathrm{~mm}$, is approximately $27 \%$ greater at the higher current density. The maximum in $\vec{u}_{g} \cdot \vec{e}_{y}$ is approximately $2 \%$ higher, as a result of the increased volume fraction (see Eqs. (48), (49) and the discussion above). Fig. 15 shows the corresponding profiles of the volumetric $\mathrm{H}_{2}$ evolution current density, $2 j_{\mathrm{H}_{2}}$ and the overpotential, $\eta_{\mathrm{H}_{2}}$ at the end of charge, $t=1321 \mathrm{~s}$, for $I_{\mathrm{appl}}=15 \mathrm{~A}$. 


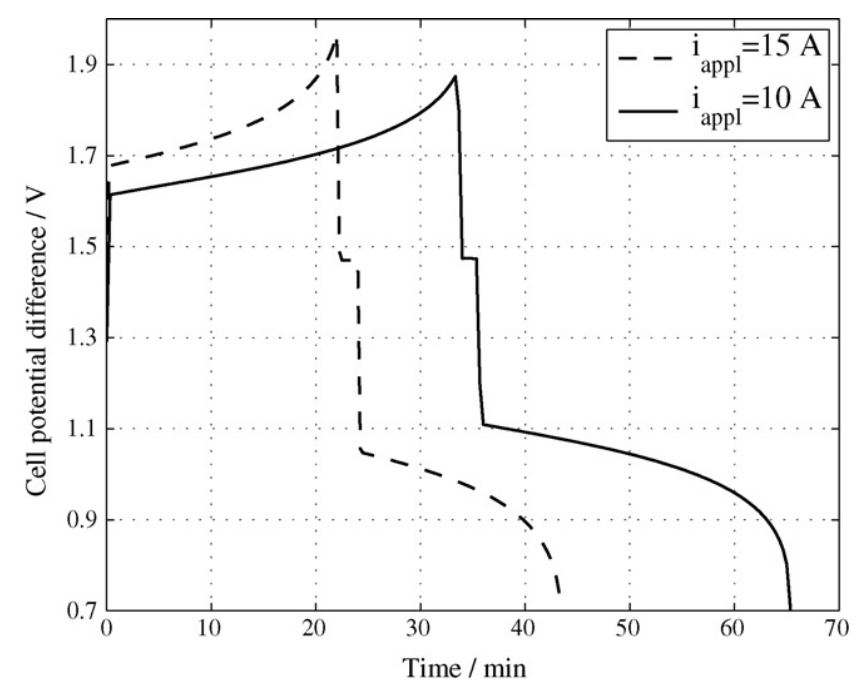

Fig. 13. Simulated cell potential difference, $E_{\text {cell }}$ curves during charge/discharge for two different applied currents, $I_{\mathrm{appl}}=10 \mathrm{~A}$ and $I_{\text {appl }}=15 \mathrm{~A} ; c_{3}^{0}=c_{4}^{0}=1080 \mathrm{~mol} \mathrm{~m}^{-3}$, $Q=1 \mathrm{~mL} \mathrm{~s}^{-1}$ and $d_{g}=50 \mu \mathrm{m}$ in both cases. The other parameter values are given in Tables 2-5. For both current densities, $S O C=0.794$ at the end of charge: $t=2017 \mathrm{~s}$ for $I_{\mathrm{appl}}=10 \mathrm{~A}$ and $t=1321 \mathrm{~s}$ for $I_{\mathrm{appl}}=10 \mathrm{~A}$.
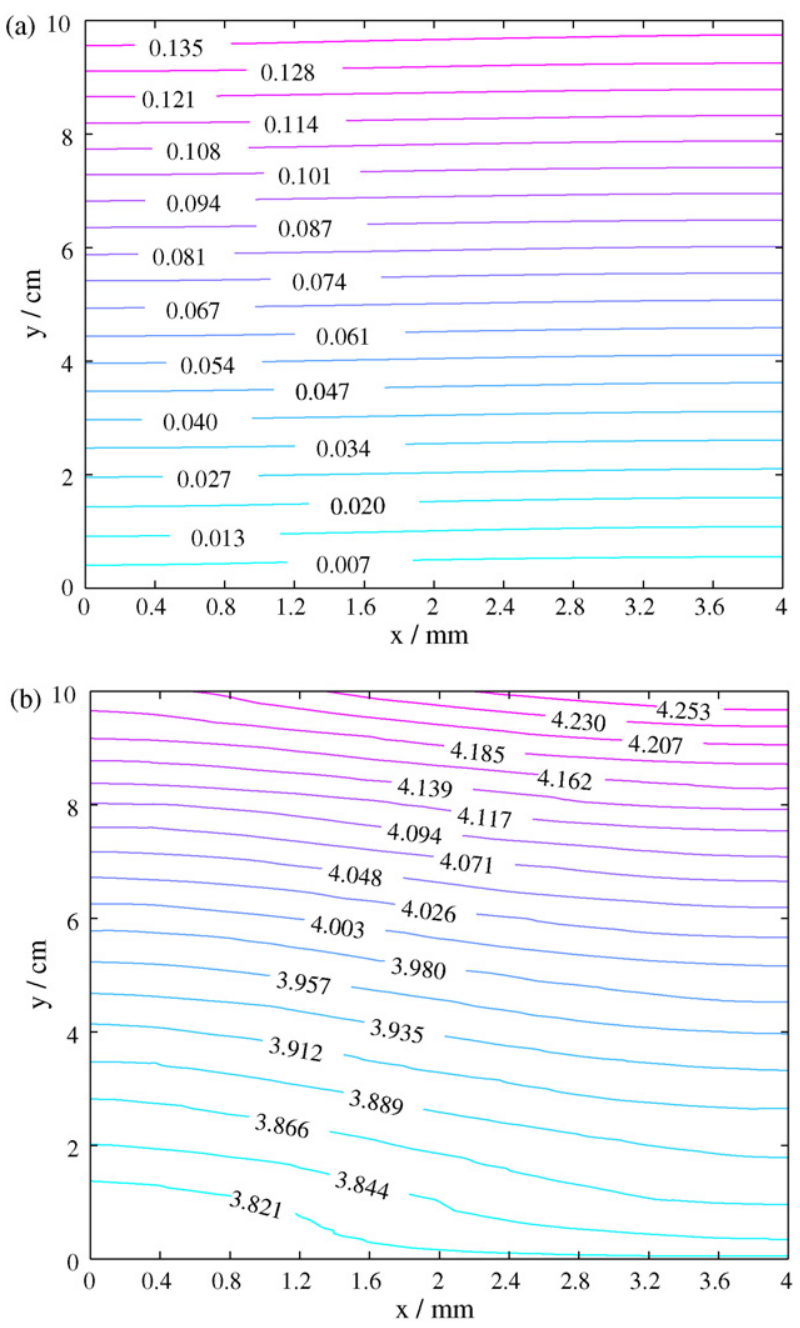

Fig. 14. (a) Distribution of the gas volume fraction, $\alpha_{g}$ and (b) the $y$ component of the gas velocity, $\vec{u}_{g} \cdot \vec{e}_{y}$ in $\mathrm{mm} \mathrm{s}^{-1}$ at the end of charge ( $\left.t=1321 \mathrm{~s}\right)$ in the case $I_{\text {appl }}=15$ A in Fig. 13 .
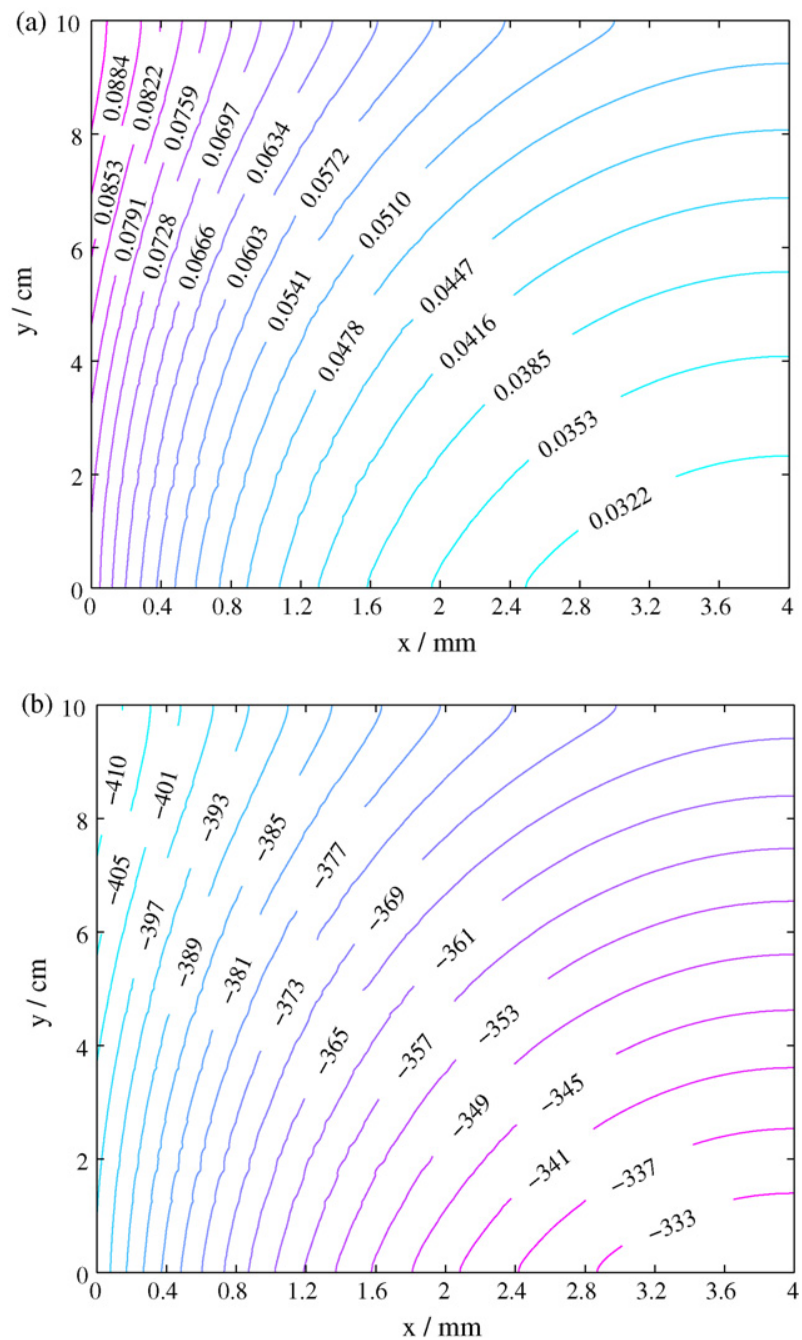

Fig. 15. (a) Distribution of the volumetric $\mathrm{H}_{2}$ evolution current density, $2 j_{\mathrm{H}_{2}}$ in $\mathrm{Acm}^{-3}$ and (b) the overpotential, $\eta_{\mathrm{H}_{2}}$ in $\mathrm{mV}$ at the end of charge $(t=1321 \mathrm{~s})$ in the case $I_{\mathrm{appl}}=15 \mathrm{~A}$ in Fig. 13.

Comparisons with Fig. 4(b) and (d), respectively, for $I_{\text {appl }}=10 \mathrm{~A}$, reveal that the volumetric current density is substantially higher and the overpotential is markedly lower, as a result of the increased applied current: the maximum in $2 j_{\mathrm{H}_{2}}$ is approximately $75 \%$ greater and the minimum is approximately $17 \%$ greater. The increased volume fraction of gas is, therefore, primarily a consequence of the faster rate of $\mathrm{H}_{2}$ evolution. The modest increase in the gas velocity plays only a minor role in reducing the gas volume fraction, $\alpha_{g}$.

\subsection{Bubble diameter effects}

The average (equivalent) diameter of the bubbles formed from gas evolution can range from $25 \mu \mathrm{m}$ to $100 \mu \mathrm{m}$, depending on the operating conditions $[14,15,47]$. In a porous electrode, the diameter cannot exceed the largest pore diameter, typically in the range $100-800 \mu \mathrm{m}$ for the porous carbon electrodes used in all-valadium RFB [42]; a value of $172 \mu \mathrm{m}$ was used in this study [44]. In order to investigate the effects of the bubble diameter, simulations were performed using values of $d_{g}=25 \mu \mathrm{m}$ and $d_{g}=100 \mu \mathrm{m}$, representing the two extremes of the reported values. In the simulations, the cell was charged at $I_{\mathrm{appl}}=10 \mathrm{~A}$, with $c_{3}^{0}=c_{4}^{0}=1080 \mathrm{~mol} \mathrm{~m}^{-3}$ and $Q=1 \mathrm{~mL} \mathrm{~s}^{-1}$, to the equivalent state of charge for the corresponding calculation shown in Fig. 2, where $d_{g}=50 \mu \mathrm{m}$. Fig. 16 shows 

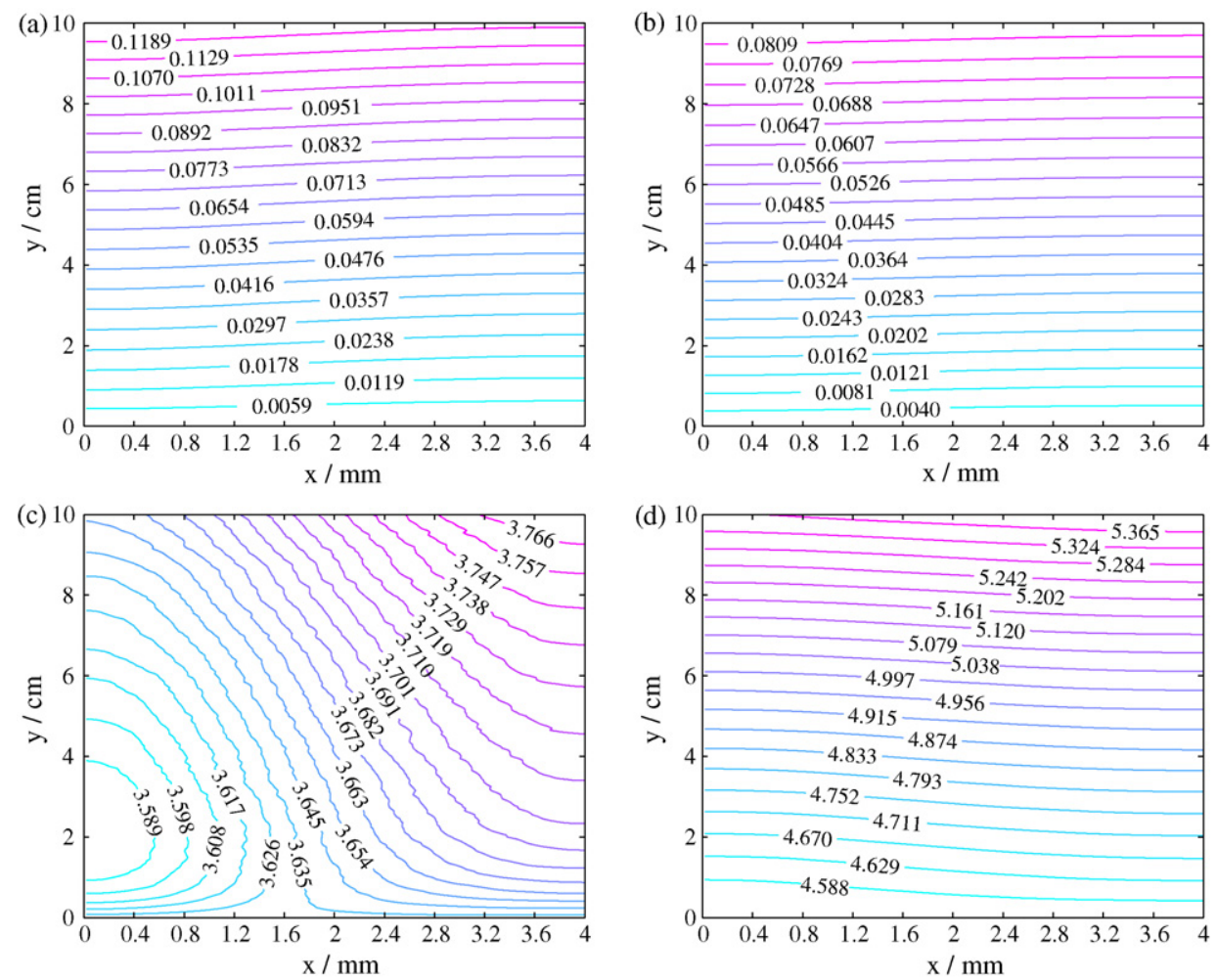

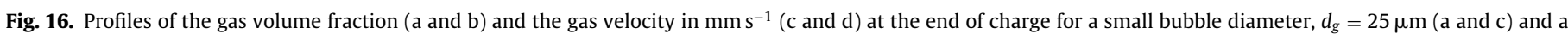
large bubble diameter, $d_{g}=100 \mu \mathrm{m}$ (b and d); $I_{\text {appl }}=10 \mathrm{~A}, c_{3}^{0}=c_{4}^{0}=1080 \mathrm{~mol} \mathrm{~m}^{-3}$ and $Q=1 \mathrm{~mL} \mathrm{~s}^{-1}$.

profiles of the gas volume fraction $\alpha_{g}$ and the $y$ component of the gas velocity $\vec{u}_{g} \cdot \vec{e}_{y}$ (in $\mathrm{mm} \mathrm{s}^{-1}$ ) at the end of charge. Fig. 16(a) and (c) corresponds to $d_{g}=25 \mu \mathrm{m}$ and Fig. 16(b) and (d) corresponds to $d_{g}=100 \mu \mathrm{m}$. These figures are to be compared with Figs. 2(b) and $8(\mathrm{~b})$, for the case $d_{g}=50 \mu \mathrm{m}$. The maximum in $\alpha_{g}$, which is attained at $y=10 \mathrm{~cm}, x=0 \mathrm{~mm}$ in all cases, increases as the bubble diameter is increased; the value for $d_{g}=25 \mu \mathrm{m}$ is approximately $47 \%$ greater than the value for $d_{g}=100 \mu \mathrm{m}$. Likewise, there is a dramatic increase in $\vec{u}_{g} \cdot \vec{e}_{y}$, with the maximum value, at $y=10 \mathrm{~cm}$, $x=4 \mathrm{~mm}$, increasing by approximately $42 \%$.

Eq. (12) indicates that the slip velocity increases with an increase in the bubble diameter, for a fixed pressure gradient, which leads to an increase in the gas velocity, given by Eq. (9). Physically, the drag is proportional to surface area of the bubble ( or $d_{g}^{2}$ ) and buoyancy is proportional to the bubble volume (or $d_{g}^{3}$ ). Larger bubbles engender a higher slip velocity, leading to a higher gas velocity. The higher gas velocity removes the bubbles at a faster rate, thus lowering the gas volume fraction. This decrease in the gas volume fraction will tend to reduce the slip velocity but any such reduction is outweighed by the increase due to the bubble diameter effect.

\section{Conclusions}

A model for $\mathrm{H}_{2}$ evolution during charge in the negative halfcell of an all-vanadium redox flow battery has been developed. The dynamic conservation equations for charge, mass and momentum were coupled to a detailed description of the electrochemical reactions. Bubble formation in the negative electrode was incorporated, taking into account the consequent reduction in the liquid electrolyte volume and the transfer of momentum between the gas and liquid phases. Evolved $\mathrm{H}_{2}$, in the form of bubbles, impacts performance through partial occlusion of the flow of the electrolyte, a reduction in the active surface area for reaction, and reduced mass and charge transport coefficients. Comparisons between numerical simulations and experimental data, for different vanadium concentrations and electrolyte flow rates, demonstrate good qualitative and quantitative agreement.

Comparing the simulation results to those from a model that neglects $\mathrm{H}_{2}$ evolution, it was demonstrated that the formation of $\mathrm{H}_{2}$ reduces the efficiency of the battery. The main cause is partial consumption of the applied current in order to drive the $\mathrm{H}_{2}$ reaction, reducing the current density associated with the redox reaction in the negative electrode.

The presence of the bubbles was found not to affect the electrolyte flow field significantly. This is likely to be a consequence of the relatively small volume fraction of gas and the large density difference between the two phases. The mean linear electrolyte flow rate appears, on the other hand, to strongly affect the volume of $\mathrm{H}_{2}$ in the electrode during charge, by virtue of the rate of bubble removal through the outlet. For an increasing applied current density it was found that the gas volume fraction inside the electrode increases, at a given state of charge. The results suggest that a high flow rate could be used to minimise this increase in gas volume.

The equivalent diameter of the bubbles was shown to exert a strong influence on the gas volume fraction. As the bubble diameter is increased, the gas velocity is enhanced by increased buoyancy, leading to a reduction in the gas volume fraction in the negative electrode. The differences in the gas velocities and gas volume fractions between the smallest and largest reported values of the bubble diameter were found to be appreciable.

\section{Acknowledgements}

The authors would like to acknowledge funding from the Technology Strategy Board, UK, and partnership with Re-Fuel Ltd and Scottish Power, from which the present work has benefited. 


\section{References}

[1] C. Ponce-de-Léon, A. Frías-Ferrer, J. González-Garcia, D.A. Szánto, F.C. Walsh, J. Power Sources 160 (2006) 716.

[2] M. Skyllas-Kazacos, C. Menictas, in: Proceedings, Intelec, Melbourne, 1997.

[3] A. Pellegri, P.M. Spaziante, UK Patent GB 2030 349A (July 1978).

[4] E. Sum, M. Skyllas-Kazacos, J. Power Sources 15 (1985) 179.

[5] M. Skyllas-Kazacos, F. Grossmith, J. Electrochem. Soc. 134 (1987) 2950.

[6] M.Y. Christi, Airlift Bioreactors, Elsevier Science Publications, 1989.

[7] J. Newman, W. Tiedemann, J. Electrochem. Soc. 144 (1997) 3081.

[8] C.Y. Wang, W.B. Gu, B.Y. Liaw, J. Electrochem. Soc. 145 (1998) 3407.

[9] T.F. Fuller, M. Doyle, J. Newman, J. Electrochem. Soc. 141 (1994) 1.

[10] T.I. Evans, T.V. Nguyen, R.E. White, J. Electrochem. Soc. 136 (1989) 328

[11] A.A. Shah, M.J. Watt-Smith, F.C. Walsh, Electrochim. Acta 53 (2008) 8087

[12] M. Li, T. Hikihara, IEICE Trans. Fundamentals E91-A (7) (2008) 1741.

[13] D.P. Scamman, G.W. Reade, E.P.L. Roberts, J. Power Sources 189 (2009) 1220.

[14] H. Vogt, Electrochim. Acta 25 (1980) 527.

[15] D. Ziegler, J.W. Evans, J. Electrochem. Soc. 103 (1986) 567.

[16] L.J.J. Janssen, Electrochim. Acta 23 (1978) 81

[17] P. Boissonneau, P. Byrne, J. Appl. Electrochem. 30 (2000) 767.

[18] F. Hine, M. Yasuda, R. Nakamura, T. Noda, J. Electrochem. Soc. 122 (1975) 1185

[19] A.A. Dahlkild, J. Fluid Mech. 428 (2001) 249.

[20] R. Wedin, A.A. Dahlkild, Ind. Eng. Chem. Res. 40 (2001) 5228.

[21] M.D. Mat, K. Aldas, O.J. Ilegbusi, Int. J. Hydrogen Energy 29 (2004) 1015.

[22] M.D. Mat, K. Aldas, Int. J. Hydrogen Energy 30 (2005) 411.

[23] M. Ishii, N. Zuber, AIChE J 25 (1979) 834.

[24] M. Manninen, V. Taivassalo, S. Kallio, On the Mixture Model for Multiphase Flow Technical Report, VTT Publications 288, Technical Research Centre of Finland, 1996.

[25] Ch. Fabjan, J. Garche, B. Harrer, L. Jörissen, C. Kolbeck, F. Philippi, G. Tomazic, F. Wagner, Electrochim. Acta 47 (2001) 825.

[26] M. Gattrell, J. Park, B. MacDougall, J. Apte, S. McCarthy, C.W. Wu, J. Electrochem. Soc. 151 (2004) 123.

[27] M.M. Saleh, Solid State Electrochem. 11 (2007) 811.
[28] M.M. Saleh, M.H. El-Ankily, M.S. El-Deab, B.E. El-Anadouli, Bull. Chem. Soc. Jpn. 79 (2006) 1711.

[29] J. Newman, Electrochemical Systems, Prentice Hall, Engelwood Cliffs, NJ, 1991.

[30] G. Marrucci, L. Nicodemo, Chem. Eng. Sci. 22 (1967) 1257.

[31] R.A. Freeze, J.A. Cherry, Groundwater, Prentice-Hall, New Jersey, 1979.

[32] G. Ahmadi, D. Ma, Int. J. Multiphase Flow 16 (1990) 323.

[33] D.A. Drew, Ann. Rev. Fluid Mech. 15 (1980) 261

[34] C. Crowe, M. Sommerfeld, Y. Tsuji, Multiphase Flows with Particles and Droplets, CRC Press, Boca Raton, FL, 1998.

[35] R. Clift, J.R. Grace, M.E. Weber, Bubbles, Drops and Particles, Academic Press, London, 1978.

[36] R.F. Probstein, Physicochemical Hydrodynamics, Butterworth Publishers, MA, 1989.

[37] B. Bird, W. Stewart, E. Lightfoot, Transport Phenomena, second ed., John Wiley and Sons, NY, 2002.

[38] A.A. Shah, P.C. Sui, G.S. Kim, S. Ye, J. Power Sources 166 (2007) 1.

[39] A.A. Shah, F.C. Walsh, J. Power Sources 185 (2008) 287.

[40] A.A. Shah, T.R. Ralph, F.C. Walsh, J. Electrochem. Soc. 156 (2009) B465.

[41] D.M. Bernadi, M.W. Verbrugge, AIChE J. 37 (1991) 1151.

[42] J. González-Garciá, P. Bonete, E. Expósito, V. Montiel, A. Aldaz, R. TorregrosaMaciá, J. Mater. Chem. 9 (1999) 419.

[43] N. Vatistas, P.F. Marconi, M. Bartolozzi, Electrochim. Acta 36 (1991) 339.

[44] R. Carta, S. Palmas, A.M. Polcaro, G. Tola, J. Appl. Electrochem. 21 (1991) 793.

[45] T. Yamamura, M. Watanabe, T. Yano, Y. Shiokawa, J. Electrochem. Soc. 152 (2005) A830.

[46] S. Motupally, A.J. Becker, J.W. Weidner, J. Electrochem. Soc. 147 (2000) A3171.

[47] L.J.J. Janssen, J.G. Hoogland, Electrochim. Acta 15 (1970) 1013.

[48] M. Pourbaix, Atlas of Electrochemical Equilibria in Aqueous Solutions, second ed., NACE International, Houston, 1974.

[49] R. Mills, Phys. Chem. 77 (1973) 685.

[50] T.E. Springer, T.A. Zawodinski, S. Gottesfeld, J. Electrochem. Soc. 138 (1991) A2334.

[51] M.W. Verbrugge, R.F. Hill, J. Electrochem. Soc. 137 (1990) 886.

[52] J.C. Brown, Tappi J. 33 (1950) 130.

[53] J.L. Fales, N.E. Vandeborough, Electrochem. Soc. Proc. 86 (1986) 179. 